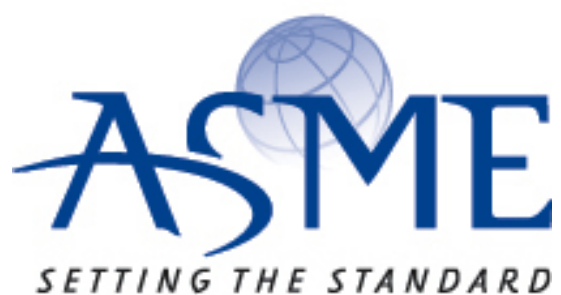

SETTING THE STANDARD

\section{American Society of Mechanical Engineers}

ASME Accepted Manuscript Repository

Institutional Repository Cover Sheet

ASME Paper Title: Analytical solutions to non-uniform surface heat transfer with volumetric sources

in magnetohydrodynamic duct flow

Authors: $\quad$ Michael Bluck

ASME Journal Title: Journal of Heat Transfer

Volume/Issue

Date of Publication (VOR* Online) _ 08/02/18

ASME Digital Collection URL:

DOI: $\quad \quad 10.1115 / 1.4042776$

*VOR (version of record) AAM published early online 


\title{
Analytical solutions to non-uniform surface heat transfer with volumetric sources in magnetohydrodynamic duct flow
}

\author{
Michael J Bluck \\ Mechanical Engineering Dept. Imperial College, London
}

\begin{abstract}
A detailed understanding of the flow of a liquid metal in a rectangular duct subject to a strong transverse magnetic field is vital in a number of engineering applications, notably for proposed blanket technologies for fusion reactors. Fusion reactors offer the potential for clean base-load energy and their development is now entering an engineering phase where the practical means by which the energy released can be converted into useful heat must be addressed. To such ends, this article considers the convective heat transfer processes for fully developed laminar magnetohydrodynamic (MHD) flows in rectangular ducts of the kind proposed in some blanket designs. Analytical solutions which incorporate the non-uniformity of peripheral temperature and heat flux and the effect of volumetric heating, are developed as functions of magnetic field strength and duct aspect ratio. A distinct feature of these MHD problems, not yet addressed in the literature, is that unlike the conventional characterisation of heat transfer by a Nusselt number, it is necessary to generalise the concept to vectors and matrices of Nusselt coefficients, due to the extreme anisotropy of both the flow and heating. The new analytical results presented here capture more complex heat transfer behaviour than non-MHD flows and in particular chracterize the importance of aspect ratio. The importance of these new results lie not only in the improved understanding of this complex process, but also in the provision of characterisations of convective heat transfer which underpin progress toward systems scale simulations of fusion blanket technology which will be vital for the realisation of practical fusion reactors.
\end{abstract}

Keywords:

Magnetohydrodynamics, Nusselt number, Heat transfer, Shercliff flow, Hunt flow, Fusion blanket

\section{Introduction}

The flow of liquid metals in strong magnetic fields is of great importance to future ambitions in nuclear fusion technology. Liquid metal can serve a dual role, firstly as a medium for heat removal and secondly tritium generation within components known as blankets $[1,2]$. In such designs, the flow often occurs in complex networks of rectangular ducts, immersed in the intense magnetic field used to contain the plasma and a neutron field produced (directly or indirectly) by the D-T reaction. The simulation of such flows and their related heat transfer processes is important for the realisation of viable fusion blanket designs. Detailed magnetohydrodynamic CFD is able, in principle, to simulate many of these processes, but at great computational expense $[3,4]$. As a result, the simulation by such means, of whole fusion blanket plant networks in a range of steady state and transient conditions is well beyond current and foreseeable computational capacity.

A broadly similar conclusion can be made of nuclear fission thermal hydraulics; CFD is a vital tool, but unable to effectively model whole system behaviour. As a result, for fission, systems codes have become the mainstay for the study of thermal hydraulics (eg RELAP5, COBRA-TF, TRAC/TRACE, etc). These models reduce the thermal hydraulic problem to effectively one dimensional flows via a cross-sectional integration, incorporating the physical complexity of wall friction, tur- bulence and wall heat transfer, etc, via constitutive models characterized in terms of non-dimensional quantities such as friction factors, Reynolds and Nusselt numbers.

In a fission systems code, the dynamics of such a flow are modelled via a system of equations of the form

$$
\frac{\partial U_{m}}{\partial t}+U_{m} \frac{\partial U_{m}}{\partial Z}=-\frac{1}{\rho} \frac{\partial P}{\partial Z}-\frac{2 f}{d_{h}} U_{m}^{2}
$$

where $Z$ is an axial coordinate along the channel, $U_{m}$ is the mean liquid velocity, $P$ the pressure, $d_{h}$ is the hydraulic diameter and $\rho$ is the liquid density. The wall friction is taken into account through the Fanning friction factor $f$ which is a function of Reynolds number Re.

Energy flow into and along channels is considered via models of the form

$$
\rho c_{v} U_{m} A \frac{\partial T_{m}}{\partial Z}=\Gamma Q^{\prime \prime}
$$

where $T_{m}$ is the liquid bulk temperature, $c_{v}$ is the liquid heat capacity and $A$ is the channel cross sectional area. $\Gamma$ is the wetted perimeter and $Q^{\prime \prime}$ is the wall heat flux into (or out of) the channel. Constitutive models relate the wall heat flux $Q^{\prime \prime}$ to the wall temperature $T_{w}$ and bulk liquid temperature $T_{m}$, characterising them as Nusselt numbers. Note that equations (1) and (2) are simplifications - systems codes typically incorporate 


\author{
Nomenclature \\ $\Gamma \quad$ Wetted perimeter (m). \\ $\mu \quad$ Fluid magnetic permeability $\left(\mathrm{Hm}^{-1}\right)$. \\ $v \quad$ Kinematic viscosity $\left(\mathrm{m}^{2} \mathrm{~s}^{-1}\right)$. \\ $\rho \quad$ Fluid density $\left(\mathrm{kgm}^{-3}\right)$. \\ $\sigma_{f} \quad$ Fluid electrical conductivity $\left(\mathrm{Sm}^{-1}\right)$. \\ $\sigma_{w} \quad$ Wall electrical conductivity $\left(\mathrm{Sm}^{-1}\right)$. \\ A Duct cross-sectional area $\left(\mathrm{m}^{2}\right)$. \\ a Non-dimensional duct half-width. \\ $b \quad$ Non-dimensional duct half-height. \\ $B_{x}^{0} \quad$ Applied $x$-directed magnetic field $\left(\mathrm{Wb} \mathrm{m}^{-2}\right)$. \\ $B_{z} \quad$ Induced magnetic field $\left(\mathrm{Wb} \mathrm{m}^{-2}\right)$. \\ $d_{h} \quad$ Hydraulic diameter (m). \\ $h \quad$ Dimensionless magnetic field. \\ Ha Hartmann number.
}

$\begin{array}{ll}N u & \text { Nusselt number. } \\ p & \text { Pressure }(\mathrm{Pa}) . \\ P o & \text { Poisueille number. } \\ P r & \text { Prandtl number. } \\ q^{\prime \prime} & \text { Heat flux }\left(\mathrm{Wm}^{-2}\right) \\ q^{\prime \prime \prime} & \text { Volumetric heating rate }\left(\mathrm{Wm}^{-3}\right) . \\ R e & \text { Reynolds number. } \\ T & \text { Temperature profile }(\mathrm{K}) . \\ t & \text { Dimensionless temperature. } \\ T_{m} & \text { Bulk temperature }(\mathrm{K}) . \\ T_{w} & \text { Wall temperature }(\mathrm{K}) \\ U & \text { Velocity profile }\left(\mathrm{ms}^{-1}\right) \\ u & \text { Dimensionless velocity. } \\ U_{m} & \text { Mean velocity }\left(\mathrm{ms}^{-1}\right)\end{array}$

multiple dynamical and energy equations describing the different phases and contain additional coupling terms to account for phase change.

Radial heat conduction within channel walls is also taken into account via corresponding 1-dimensional Poisson equations which are coupled with the energy equations (2) within the channels. This coupling requires heat transfer coefficients relating (for instance) mean wall temperatures $\bar{T}_{w}$, wall heat fluxes $\overline{Q^{\prime \prime}}$ and bulk temperature, and are typically characterized as Nusselt numbers via

$$
\overline{Q^{\prime \prime}}=\frac{k}{d_{h}} N u\left(\bar{T}_{w}-T_{m}\right)
$$

Given appropriate expressions for friction factor and Nusselt numbers and the like, these equations are solved using an appropriate finite volume scheme, and, being one dimensional, can be solved very rapidly. In the majority of fission cases $Q^{\prime \prime}$ and/or $T_{w}$ can be reasonably assumed to be uniform around the channel perimeter and the resulting heat transfer can be characterized by peripherally mean Nusselt numbers.

For fusion blanket designs comprising helium and/or water as a working fluid, such systems level models may be suitable. However, there are often cases when the wall heat flux may be strongly anisotropic: The first wall bears a great deal of the surface heat flux and a channel wall in proximity to and facing the first wall will experience much greater heat flux than other walls. In addition, for those designs incorporating liquid metal (usually a PbLi eutectic), the standard constitutive models (friction factors, Nusselt numbers, etc) are inadequate as they fail to incorporate the radical effects of the intense magnetic field on the flow. In proximity to Hartman and side-walls and in the core, the flow is very different (particularly for Hunt flow) from the non-MHD case $[5,6]$. A peripherally mean Nusselt number is, then, a potentially poor characterization of the heat transfer mechanism. In addition to these effects, volumetric heating due to the potentially intense neutron flux must also be taken into account. For such cases, then, energy flow into and along channels must be considered via models of the form

$$
\rho c_{\nu} U_{m} A \frac{\partial T_{m}}{\partial Z}=\sum_{i=1}^{4} \Gamma_{i} \overline{Q_{i}^{\prime \prime}}+A q^{\prime \prime \prime}
$$

rather than (2), where the $\overline{Q_{i}^{\prime \prime}}$ are the mean heat fluxes on each of the four duct walls, each of length $\Gamma_{i}$ and $q^{\prime \prime \prime}$ is the volumetric heat source. The coupling of energy equations such as (4) to the radial heat conduction within channel walls will generally require appropriate heat transfer coefficients enabling mean wall temperature, mean wall heat flux and bulk temperature to be related, similar to the non-MHD case. A key difference with the MHD cases considered here is that the heat transfer effects of the distorted flow profile and possibly inhomogeneous wall heating is insufficiently well characterized by an expression such as (3).

For $H_{1}$ cases, the underlying assumption is that the wall thermal conductivity is very large such that there is negligible variation in the specified wall temperature $T_{w}$ around the periphery. Four wall heat fluxes, $Q_{i}^{\prime \prime}$ result and are formally related to the wall and bulk temperatures via

$$
\mathbf{Q}^{\prime \prime}=\frac{k}{d_{h}} \mathbf{N u}\left(T_{w}-T_{m}\right)
$$

where $\mathrm{Nu}$ is a four-vector of Nusselt numbers.

The $\mathrm{H}_{2}$ case, where the essential assumption is that the wall thermal conductivity is poor and that wall heat flux is specified, is more complex still. In this case, there are four (mean) wall temperatures and four specified heat fluxes, leading to sixteen 'Nusselt' numbers, which can be characterized as a $4 \times 4$ matrix. Formally, this 'Nusselt matrix' $[\mathbf{N u}]$ is defined as

$$
\mathbf{Q}^{\prime \prime}=\frac{k}{d_{h}}[\mathbf{N u}]\left(\mathbf{T}_{w}-\mathbf{T}_{m}\right)
$$

For the purposes of this analysis, the flow is assumed to be laminar and fully-developed. In the case of strong magnetic 
fields within fusion blanket applications, these are frequently good approximations. Flows are typically quite low $\operatorname{Re}[1]$; strong magnetic fields can suppress turbulence to a significant degree and considerably reduce the development length [7]. Furthermore, buoyancy forces will be neglected although this simplifying assumption is questionable in certain designs. As explained above, there are a number of heat transfer mechanisms; heat may be transferred from the duct walls to the liquid metal via forced convection and heat may be generated within the liquid metal directly via neutron heating, joule heating and viscous heating. In this study we will ignore both joule and viscous heating effects, considering only cases where neutron heating is dominant. Furthermore, we will assume that this volumetric heating is uniform.

The heat transfer problem is dependent on the dynamics of the flow. In this paper we restrict ourselves to axial, fullydeveloped laminar flow in rectangular ducts. The flow profile in the MHD case is very different from conventional flows within the same geometry and is strongly dependent on the electrical conductivity of the bounding walls and the applied magnetic field. The problem of determining the flow profile in these cases then reduces to two coupled partial differential equations subject to magnetic boundary conditions dependent on the wall conductivity. An analytical solution for the case of perfectly insulating walls was first obtained by Shercliff [5]. The Shercliff flow is characterised by a flattening of the core flow and increasingly strong shear near the walls, most prominently at the walls perpendicular to the applied magnetic field (so-called Hartmann walls). Further analytical solutions were obtained for arbitrary, thin conducting walls by Hunt [6]. More recently, analytical solutions for certain relevant Hunt-type flows have been developed for arbitrarily thick walls [8]. The so-called Hunt-II case, considered here consists of conducting Hartmann walls and insulating side-walls (those walls parallel to the applied magnetic field). Such Hunt-II flows are characterised by a flattening of the core and strong shear at Hartmann walls, as with Shercliff flows, but also exhibit the development of strong jet flows near the side walls.

Recent work by the authors $[9,10]$ has led to some analytical results for Shercliff and Hunt-II flows restricted to uniform peripheral wall temperature and heat flux. Such solutions also exist for flow between parallel plates and flows in circular channels [11, 12], and for 1-D heat transfer [13]. There are also some experimental and a number of numerical studies of heat transfer for Shercliff and related cases [14, 15, 16, 17, 18, 19]. The major shortcoming of all of these studies is that they fail to capture both the volumetric and strongly anisotropic surface heat transfer inherent in fusion blanket applications and their dependence on aspect ratio.

In this article we develop analytical solutions for Shercliff and Hunt type-II flows with non-uniform peripheral wall temperature, non-uniform peripheral heat flux and uniform volumetric heating. The results presented here provide the heat transfer correlations which underpin whole plant simulation tools that will be essential for the engineering implementation of fusion technology. To the author's knowledge this work is novel.

\section{Problem Formulation}

Referring to Fig. 1, the momentum equation in a fully developed MHD flow in a rectangular duct of size $-a d_{h} \leq X \leq a d_{h}$ and $-b d_{h} \leq Y \leq b d_{h}$ (where $d_{h}$ is the hydraulic diameter), subject to an applied $X$-directed magnetic field $B_{x}^{0}$ is given by

$$
v\left(\frac{\partial^{2} U}{\partial X^{2}}+\frac{\partial^{2} U}{\partial Y^{2}}\right)-\frac{1}{\rho} \frac{\partial p}{\partial Z}+\frac{1}{\rho \mu} \frac{\partial B_{z}}{\partial X} B_{x}^{0}=0
$$

The flow of conducting fluid generates an induced magnetic field $B_{z}$, satisfying

$$
\frac{1}{\mu \sigma}\left(\frac{\partial^{2} B_{z}}{\partial X^{2}}+\frac{\partial^{2} B_{z}}{\partial Y^{2}}\right)+B_{x}^{0} \frac{\partial U}{\partial X}=0
$$

Where $U$ is the velocity, $v$ is the kinematic viscosity, $\mu$ the magnetic permeability, $\rho$ the density and $\sigma_{f}$ the electrical conductivity of the fluid.

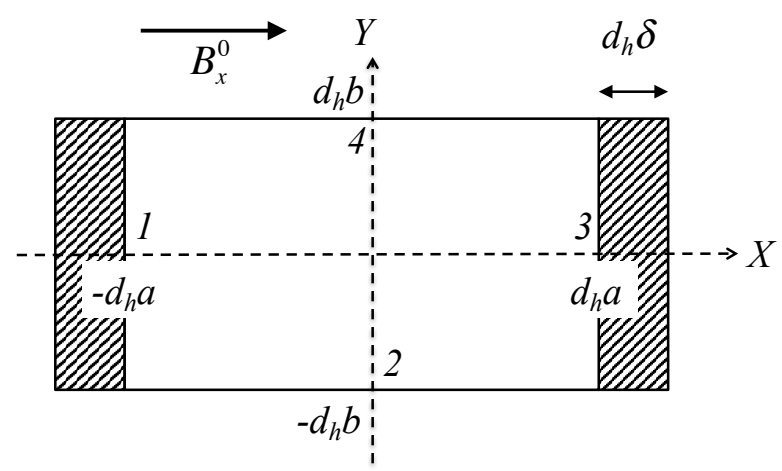

Figure 1: Duct coordinate system and wall numbering

Non-dimensionalising, by setting

$$
\begin{aligned}
& x=\frac{X}{d_{h}}, y=\frac{Y}{d_{h}}, z=\frac{Z}{d_{h}} \\
& u=\frac{U}{U_{m}}
\end{aligned}
$$

where

$$
U_{m}=\frac{1}{A} \int_{A} U d A
$$

and

$$
h=\frac{1}{\mu} \frac{1}{\sqrt{\rho v \sigma_{f}}} \frac{1}{U_{m}} B_{z}
$$

we obtain

$$
\frac{\partial^{2} u}{\partial x^{2}}+\frac{\partial^{2} u}{\partial y^{2}}+H a \frac{\partial h}{\partial x}=2 P o
$$

where

$$
H a=B_{x}^{0} d_{h} \sqrt{\frac{\sigma_{f}}{\rho v}}
$$


and the Poiseuille number is defined as

$$
P o=-\frac{1}{\rho v} \frac{\partial p}{\partial Z} \frac{d_{h}^{2}}{2 U_{m}}
$$

The no-slip condition requires that $u=0$ at the wall. The nondimensional induced magnetic field $h$ satisfies

$$
\frac{\partial^{2} h}{\partial x^{2}}+\frac{\partial^{2} h}{\partial y^{2}}+H a \frac{\partial u}{\partial x}=0
$$

in the fluid region. For Shercliff flows, the induced magnetic field vanishes at the wall (and is neglected within the wall). For the Hunt II problem, the wall has finite electrical conductivity $\sigma_{w}$, and it is assumed that the induced magnetic field vanishes at the side-walls, is continuous at the Hartmann wall-fluid interface and vanishes at the external boundary of the Hartmann walls. The magnetic field within the wall satisfies a Laplace equation. The solution to this Hunt-II problem is given in [8]. Note that this solution reduces to the Shercliff solution for wholly insulating walls by setting $P_{n}=0$.

To determine the heat transfer we consider the energy equation in the fluid domain, which in steady state, fully developed flow takes the form of an advection diffusion equation with a source term, and can be written as

$$
\frac{k}{\rho c_{p}}\left(\frac{\partial^{2} T}{\partial X^{2}}+\frac{\partial^{2} T}{\partial Y^{2}}\right)=U \frac{\partial T}{\partial Z}-\frac{q^{\prime \prime \prime}}{\rho c_{p}}
$$

For now, we leave this equation in its dimensional form. The process of non-dimensionalization differs markedly between $H_{1}$ and $H_{2}$ cases and is dealt with at the beginning of sections 3.1 and 3.2 for the $H_{1}$ and $H_{2}$ cases, respectively.

\section{Analytical Solution}

\section{1. $H_{1}$ Heat transfer case}

The $H_{1}$ heat transfer case describes circumstances where the heat flux is uniform in the axial direction and the wall temperature $T_{w}$ is specified in the peripheral direction. The $H_{1}$ case is typically assumed to be representative of walls with very high thermal conductivity, leading to a negligible peripheral gradient. Under this assumption, $T_{w}$ is uniform around the periphery of the duct. Under the conditions of fully developed flow, it can be assumed that

$$
\frac{\partial T}{\partial Z}=\frac{d T_{m}}{d Z}=\frac{d T_{w}}{d Z}=\text { const }
$$

where the bulk temperature $T_{m}$ is defined as

$$
T_{m}=\frac{\int_{A} U T d A}{\int_{A} U d A}
$$

The constant in (18) can be determined by an energy balance as:

$$
\left(\overline{q^{\prime \prime}} \Gamma+q^{\prime \prime \prime} A\right) d Z=\rho c_{p} A U_{m} d T_{m}
$$

where $\overline{q^{\prime \prime}}$ is the (as yet undetermined) mean peripheral heat flux. With some rearrangement it follows that

$$
\frac{d T_{m}}{d Z}=\frac{4 \overline{q^{\prime \prime}}+d_{h} q^{\prime \prime \prime}}{k \operatorname{RePr}}
$$

We non-dimensionalize, with the non-dimensional temperature profile $t(x, y)$ being defined by

$$
t=\frac{T-T_{w}}{\left(d T_{m} / d Z\right) d_{h}}
$$

inserting these into equation (17) gives

$$
\frac{\partial^{2} t}{\partial x^{2}}+\frac{\partial^{2} t}{\partial y^{2}}=(\operatorname{RePr}) u-\frac{d_{h}}{k}\left(\frac{d T_{m}}{d Z}\right)^{-1} q^{\prime \prime \prime}
$$

We now decompose the non-dimensional temperature $t$ into the sum of two solutions $t_{1}$ and $t_{2}$. The equation and boundary conditions for $t_{1}$ are

$$
\frac{\partial^{2} t_{1}}{\partial x^{2}}+\frac{\partial^{2} t_{1}}{\partial y^{2}}=(\operatorname{RePr}) u,\left.t_{1}\right|_{\Gamma}=0
$$

The equation and boundary conditions for $t_{2}$ are

$$
\frac{\partial^{2} t_{2}}{\partial x^{2}}+\frac{\partial^{2} t_{2}}{\partial y^{2}}=-\frac{d_{h}}{k}\left(\frac{d T_{m}}{d Z}\right)^{-1} q^{\prime \prime \prime},\left.t_{2}\right|_{\Gamma}=0
$$

Considering the $t_{1}$ solution, this is the case considered in [10] and we reproduce the solution here:

$$
t_{1}=2 \operatorname{RePoPr} \sum_{n=1}^{\infty} g_{n}(x) \cos \lambda_{n} y
$$

and $g_{n}$ is similarly defined in [10].

The $t_{2}$ solution is readily obtained by separation of variables, and is given by

$$
t_{2}=\frac{d_{h}}{2 k}\left(\frac{d T_{m}}{d Z}\right)^{-1} q^{\prime \prime \prime}\left(\left(b^{2}-y^{2}\right)+\frac{4}{b} \sum_{n=1}^{\infty} \frac{(-1)^{n} \cosh \lambda_{n} x}{\lambda_{n}^{3} \cosh \lambda_{n} a} \cos \lambda_{n} y\right) \text { (27) }
$$

Given these results, $t=t_{1}+t_{2}$ can be computed and the temperature profile $T$ obtained from (22), giving

$$
\begin{aligned}
T(x, y) & =T_{w}+\frac{2 d_{h}}{k} \operatorname{Po}\left(4 \overline{q^{\prime \prime}}+d_{h} q^{\prime \prime \prime}\right) \sum_{n=1}^{\infty} g_{n}(x) \cos \lambda_{n} y \\
& +\frac{d_{h}^{2} q^{\prime \prime \prime}}{2 k}\left(\left(b^{2}-y^{2}\right)+\frac{4}{b} \sum_{n=1}^{\infty} \frac{(-1)^{n} \cosh \lambda_{n} x}{\lambda_{n}^{3} \cosh \lambda_{n} a} \cos \lambda_{n} y\right)
\end{aligned}
$$

Multiplying (28) by $U$, integrating over the cross-section and using (19) and the results in [8] and [10], it can be shown that

$$
\begin{array}{r}
T_{m}-T_{w}=\frac{d_{h}}{k}\left(4 \overline{q^{\prime \prime}}+d_{h} q^{\prime \prime \prime}\right) \frac{\int_{A} u \sum_{n=1}^{\infty} g_{n}(x) \cos \lambda_{n} y d A}{\int_{A} \sum_{n=1}^{\infty} u_{n}(x) \cos \lambda_{n} y d A} \\
+\frac{d_{h}^{2} q^{\prime \prime \prime}}{8 a b k} \int_{A}\left(\left(b^{2}-y^{2}\right)+\frac{4}{b} \sum_{n=1}^{\infty} \frac{(-1)^{n} \cosh \lambda_{n} x}{\lambda_{n}^{3} \cosh \lambda_{n} a} \cos \lambda_{n} y\right) u d A
\end{array}
$$

In these circumstances, peripherally mean surface and volume Nusselt numbers may be defined by writing (29) as

$$
T_{m}-T_{w}=\frac{d_{h}{\overline{q^{\prime \prime}}}_{k}}{\overline{N u}_{s}}+\frac{1}{k} \frac{d_{h}^{2} q^{\prime \prime \prime}}{\overline{N u}_{v}}
$$


Explicit forms of the mean surface Nusselt number can then be obtained using (29) and (30), giving

$$
\overline{N u}_{s}=\frac{\int_{A} \sum_{n=1}^{\infty} u_{n}(x) \cos \lambda_{n} y d A}{4 \int_{A} u \sum_{n=1}^{\infty} g_{n}(x) \cos \lambda_{n} y d A}
$$

The corresponding volumetric Nusselt number is similarly obtained as

$$
\begin{aligned}
\overline{N u}_{v} & =\left(\frac{1}{4 \overline{N u}_{s}}\right. \\
& \left.+\frac{1}{8 a b} \int_{A}\left(b^{2}-y^{2}+\frac{4}{b} \sum_{n=1}^{\infty} \frac{(-1)^{n} \cosh \lambda_{n} x}{\lambda_{n}^{3} \cosh \lambda_{n} a} \cos \lambda_{n} y\right) u d A\right)^{-1}
\end{aligned}
$$

Some explanation of the meaning of the volumetric Nusselt number is worthwhile. From equation (30), the difference between the wall and bulk temperatures is seen to be the sum of two terms: a term proportional to the surface heat flux $\overline{q^{\prime \prime}}$ and a term proportional to the volumetric heating $q^{\prime \prime \prime}$. For the surface Nusselt number, a corresponding heat transfer coefficient can be determined. Note that, defined in this manner, the surface heat transfer coefficient is a measure of the effectiveness of heat transfer to (from) the wall from (to) the fluid. A low surface heat transfer coefficient indicates high resistance to the flow of heat and a concomitant large contribution to the difference between the bulk temperature and the wall temperature. This is typically caused by low wall shear stresses (thick hydrodynamic boundary layers). In simple terms, the slow (relative to the bulk) moving fluid near the wall is unable to effectively advect heat away from the wall, giving rise to elevated temperatures (relative to the bulk) near the wall and a concomitant elevated wall temperature (again relative to the bulk temperature).

In the case of volumetric heating, additional heat is supplied directly to the fluid. Slow moving fluid (relative to the bulk), such as that typically found near the walls, will experience an additional elevated temperature (relative to the bulk and beyond that due to any surface heat flux), further elevating the wall temperature. Thus the volumetric Nusselt number is a measure of the excess accretion of heat within the boundary layer beyond that accreted within the bulk. A low volumetric Nusselt number indicates a large accretion of heat within the boundary layer relative to that in the bulk. This would be the case, for instance, in a typical non-MHD laminar flow profile with a relatively thick boundary layer. At the other extreme, slug flow would result in an infinite volumetric Nusselt number as there is no excess heat accretion within the (non-existent) boundary layer relative to the heat accretion within the bulk.

The results in (30), (31) and (32) adequately characterise the relationship between wall temperature $T_{w}$ and the peripherally mean heat flux $\overline{q^{\prime \prime}}$ in terms of appropriate Nusselt numbers. As explained in section 1, this, of itself, may not be adequate in the circumstances considered here. To address this, by substitution of the $\overline{q^{\prime \prime}}$ in equation (28) using equation (30), one can obtain an expression for $T(x, y)$ solely in terms of $T_{w}$ and $T_{m}$. This can then be used to compute the heat flux on each wall, from which can be obtained the mean wall heat fluxes $\overline{Q_{i}^{\prime \prime}}$ by integration.
Extensive manipulation results in a relationship of the form

$$
T_{m}-T_{w}=\frac{d_{h} \overline{Q_{i}^{\prime \prime}}}{k} \frac{1}{\overline{N u}_{s, i}}+\frac{d_{h}^{2} q^{\prime \prime \prime}}{k} \frac{1}{\overline{N u}_{v, i}}
$$

where

$$
\begin{aligned}
& \overline{N u}_{s, i}=\frac{16 a b \overline{N u}_{s} D_{i}}{\Gamma_{i}} \\
& \overline{N u}_{v, i}=\frac{\overline{N u}_{s, i} \Gamma_{i}}{\left\{4 a b\left(1-\frac{4 \overline{N u}_{s}}{\overline{N u}_{v}}\right) D_{i}-\frac{1}{2} C_{i}\right\}} \\
& C_{i}=\int_{\Gamma_{i}} \mathbf{n}_{i} \cdot \nabla\left(b^{2}-y^{2}+\frac{4}{b} \sum_{n=1}^{\infty} \frac{(-1)^{n} \cosh \lambda_{n} x}{\lambda_{n}^{3} \cosh \lambda_{n} a} \cos \lambda_{n} y\right) d \Gamma
\end{aligned}
$$

and

$$
D_{i}=\frac{\int_{\Gamma_{i}} \sum_{n=1}^{\infty} \mathbf{n}_{i} \cdot \nabla\left(g_{n}(x) \cos \lambda_{n} y\right) d \Gamma}{\int_{A} \sum_{n=1}^{\infty} u_{n}(x) \cos \lambda_{n} y d A}
$$

Using (33) allows the individual mean wall heat fluxes to be determined given the wall and bluck temperatures and the volumetric heating rate. As the terminology implies, the $\overline{N u}_{s, i}$ and $\overline{N u}_{v, i}$ represent individual wall mean surface and volumetric Nusselt numbers.

\section{2. $\mathrm{H}_{2}$ Heat transfer case}

The $H_{2}$ transfer case describes circumstances where the heat flux is uniform in the axial direction and is non-uniform in the peripheral direction (actually piecewise uniform). We follow an analysis similar to [20]. The same magnetohydrodynamic conditions arise as in the $H_{1}$ case, but the treatment of the energy equation differs somewhat. In this case we define the nondimensional temperature profile $t(x, y)$ as

$$
t=\frac{k}{\overline{q^{\prime \prime}} d_{h}}\left(T-T_{m}\right)
$$

Inserting these into equation (17) gives

$$
\frac{\partial^{2} t}{\partial x^{2}}+\frac{\partial^{2} t}{\partial y^{2}}=\left(4+\frac{d_{h} q^{\prime \prime \prime}}{\overline{q^{\prime \prime}}}\right) u-\frac{d_{h} q^{\prime \prime \prime}}{\overline{q^{\prime \prime}}}
$$

where

$$
\overline{q^{\prime \prime}}=\frac{a\left(Q_{2}^{\prime \prime}+Q_{4}^{\prime \prime}\right)+b\left(Q_{1}^{\prime \prime}+Q_{3}^{\prime \prime}\right)}{2(a+b)}
$$

is the mean surface heat flux. The boundary condition at the $i$-th wall is

$$
k \frac{\partial T}{\partial n_{i}}=Q_{i}^{\prime \prime}
$$

which take the non-dimensional form

$$
\frac{\partial t}{\partial n_{i}}=\frac{Q_{i}^{\prime \prime}}{\overline{q^{\prime \prime}}}
$$


We now decompose the non-dimensional temperature $t$ into the sum of three solutions $t_{1}, t_{2}$ and $t_{3}$. The equation and boundary conditions for $t_{1}$ are

$$
\frac{\partial^{2} t_{1}}{\partial x^{2}}+\frac{\partial^{2} t_{1}}{\partial y^{2}}=4 u, \frac{\partial t_{1}}{\partial n_{i}}=1
$$

The equation and boundary conditions for $t_{2}$ are

$$
\frac{\partial^{2} t_{2}}{\partial x^{2}}+\frac{\partial^{2} t_{2}}{\partial y^{2}}=\frac{d_{h} q^{\prime \prime \prime}}{\overline{q^{\prime \prime}}}(u-1), \frac{\partial t_{2}}{\partial n_{i}}=0
$$

The equation and boundary conditions for $t_{3}$ are

$$
\frac{\partial^{2} t_{3}}{\partial x^{2}}+\frac{\partial^{2} t_{3}}{\partial y^{2}}=0, \frac{\partial t_{3}}{\partial n_{i}}=\frac{q_{i}^{\prime \prime}}{\overline{q^{\prime \prime}}}
$$

where $q_{i}^{\prime \prime}=Q_{i}^{\prime \prime}-\overline{q^{\prime \prime}}$. This has a straightforward closed-form analytical solution given by

$$
\begin{aligned}
t_{3}= & \frac{1}{2 \overline{q^{\prime \prime}}}\left(\left(q_{1}^{\prime \prime}-q_{3}^{\prime \prime}\right) x+\left(q_{2}^{\prime \prime}-q_{4}^{\prime \prime}\right) y\right. \\
& \left.-\left(q_{1}^{\prime \prime}+q_{3}^{\prime \prime}\right) \frac{x^{2}}{2 a}-\left(q_{2}^{\prime \prime}+q_{4}^{\prime \prime}\right) \frac{y^{2}}{2 b}\right)
\end{aligned}
$$

Following [20] we can homogenise equation (43) by defining $\theta(x, y)$ as

$$
\theta(x, y)=t_{1}(x, y)-\left(\frac{x^{2}}{2 a}+\frac{y^{2}}{2 b}\right)
$$

and a simple scaling of equation (44) allows us to write:

$$
\theta(x, y)=\frac{4 \overline{q^{\prime \prime}}}{d_{h} q^{\prime \prime \prime}} t_{2}(x, y)
$$

This allows us to consider just the solution of the following equation on one quarter of the duct, due to symmetry

$$
\begin{array}{r}
\frac{\partial^{2} \theta}{\partial x^{2}}+\frac{\partial^{2} \theta}{\partial y^{2}}=4(u-1) \\
\frac{\partial \theta}{\partial x}=0, \text { on } x=0 \\
\frac{\partial \theta}{\partial x}=0, \text { on } x=a \\
\frac{\partial \theta}{\partial y}=0, \text { on } y=0 \\
\frac{\partial \theta}{\partial y}=0, \text { on } y=b
\end{array}
$$

The solution to (49) has already been obtained in [10]. We then have

$$
t=t_{1}+t_{2}+t_{3}=\left(\frac{x^{2}}{2 a}+\frac{y^{2}}{2 b}\right)+\left(1+\frac{d_{h} q^{\prime \prime \prime}}{4 \overline{q^{\prime \prime}}}\right) \theta+t_{3}
$$

It remains to compute the constant $c_{2}$ arising in the expression for $\theta$ in [10]. The determination of $c_{2}$ is achieved by applying the following constraint proposed in [20]:

$$
\int_{A} u t d A=0
$$

Defining $\theta=\tilde{\theta}+c_{2}$ we can write

$$
t=\left(\frac{x^{2}}{2 a}+\frac{y^{2}}{2 b}\right)+\left(1+\frac{d_{h} q^{\prime \prime \prime}}{4 \overline{q^{\prime \prime}}}\right)\left(\tilde{\theta}+c_{2}\right)+t_{3}
$$

Applying the constraint, shows that

$$
\begin{aligned}
& A \bar{u}\left(1+\frac{d_{h} q^{\prime \prime \prime}}{4 \overline{q^{\prime \prime}}}\right) c_{2} \\
=- & \int_{A}\left(\frac{x^{2}}{2 a}+\frac{y^{2}}{2 b}+\tilde{\theta}\right) u d A \\
- & \frac{d_{h} q^{\prime \prime \prime}}{4 \overline{q^{\prime \prime}}} \int_{A} \tilde{\theta} u d A \\
- & \frac{1}{2 \overline{q^{\prime \prime}}}\left(\left(q_{1}^{\prime \prime}-q_{3}^{\prime \prime}\right) \int_{A} u x d A+\left(q_{2}^{\prime \prime}-q_{4}^{\prime \prime}\right) \int_{A} u y d A\right. \\
& \left.-\frac{\left(q_{1}^{\prime \prime}+q_{3}^{\prime \prime}\right)}{2 a} \int_{A} u x^{2} d A-\frac{\left(q_{2}^{\prime \prime}+q_{4}^{\prime \prime}\right)}{2 b} \int_{A} u y^{2} d A\right)
\end{aligned}
$$

where $\bar{u}$ is the mean value of $u$. Inserting this back into equation (56), re-dimensionalizing and using (40) gives

$$
\begin{aligned}
T(x, y)-T_{m} & =\frac{Q_{1}^{\prime \prime} d_{h}}{k}\left(\frac{b}{2(a+b)} \alpha-\frac{1}{2} \beta_{1}+\frac{1}{4(a+b)} \gamma\right) \\
& +\frac{Q_{2}^{\prime \prime} d_{h}}{k}\left(\frac{a}{2(a+b)} \alpha-\frac{1}{2} \beta_{2}-\frac{1}{4(a+b)} \gamma\right) \\
& +\frac{Q_{3}^{\prime \prime} d_{h}}{k}\left(\frac{b}{2(a+b)} \alpha+\frac{1}{2} \beta_{1}+\frac{1}{4(a+b)} \gamma\right) \\
& +\frac{Q_{4}^{\prime \prime} d_{h}}{k}\left(\frac{a}{2(a+b)} \alpha+\frac{1}{2} \beta_{2}-\frac{1}{4(a+b)} \gamma\right) \\
& +\frac{q^{\prime \prime \prime} d_{h}^{2}}{k} \frac{\delta}{4}
\end{aligned}
$$

where

$$
\begin{aligned}
\alpha & =\frac{x^{2}}{2 a}+\frac{y^{2}}{2 b}+\tilde{\theta}-\frac{1}{A \bar{u}} \int_{A}\left(\frac{x^{2}}{2 a}+\frac{y^{2}}{2 b}+\tilde{\theta}\right) u d A \\
\beta_{1} & =x-\frac{1}{A \bar{u}} \int_{A} x u d A \\
\beta_{2} & =y-\frac{1}{A \bar{u}} \int_{A} y u d A \\
\gamma & =x^{2}-y^{2}-\frac{1}{A \bar{u}} \int_{A}\left(x^{2}-y^{2}\right) u d A \\
\delta & =\tilde{\theta}-\frac{1}{A \bar{u}} \int_{A} u \tilde{\theta} d A
\end{aligned}
$$

If we restrict the analysis to the case of entirely uniform peripheral heating $\left(\overline{q^{\prime \prime}}=Q_{i}^{\prime \prime}\right)$ we obtain

$$
T(x, y)-T_{m}=\frac{d_{h} \overline{q^{\prime \prime}}}{k} \alpha+\frac{d_{h}^{2} q^{\prime \prime \prime}}{k} \frac{\delta}{4}
$$

Pointwise $\mathrm{H}_{2}$ Nusselt numbers can be defined using (60) where evaluation at the wall gives

$$
T_{w}-T_{m}=\frac{d_{h} \overline{q^{\prime \prime}}}{k} \frac{1}{N u_{s}}+\frac{d_{h}^{2} q^{\prime \prime \prime}}{k} \frac{1}{N u_{v}}
$$

From which it follows that

$$
N u_{s}=\frac{1}{\alpha_{w}}, N u_{v}=\frac{4}{\delta_{w}}
$$


Peripherally mean Nusselt numbers $\left(\overline{N u}_{s, v}\right)$ are defined by appropriate integration of (61) along the boundary $\Gamma$, giving:

$$
\bar{T}_{w}-T_{m}=\frac{d_{h} \overline{q^{\prime \prime}}}{k} \frac{1}{\overline{N u}_{s}}+\frac{d_{h}^{2} q^{\prime \prime \prime}}{k} \frac{1}{\overline{N u}_{v}}
$$

where

$$
\overline{N u}_{s, v}=\left(\frac{1}{\Gamma} \int_{\Gamma} \frac{1}{N u_{s, v}} d s\right)^{-1}
$$

Returning to the general case (58), using the definition of the peripherally mean $\mathrm{H}_{2}$ Nusselt numbers and the definition of the mean wall heat flux (40), gives

$$
T_{w}-T_{m}=\frac{d_{h}}{k} \sum_{i=1}^{4} \frac{Q_{i}^{\prime \prime}}{N u_{s, i}}+\frac{d_{h}^{2} q^{\prime \prime \prime}}{k} \frac{1}{N u_{v}}
$$

where the Nusselt numbers associated with each side are defined as

$$
\begin{aligned}
N u_{s, 1} & =\frac{4(a+b)}{2 b N u_{s}^{-1}-2(a+b) \beta_{1}+\gamma} \\
N u_{s, 2} & =\frac{4(a+b)}{2 a N u_{s}^{-1}-2(a+b) \beta_{2}-\gamma} \\
N u_{s, 3} & =\frac{4(a+b)}{2 b N u_{s}^{-1}+2(a+b) \beta_{1}+\gamma} \\
N u_{s, 4} & =\frac{4(a+b)}{2 a N u_{s}^{-1}+2(a+b) \beta_{2}-\gamma}
\end{aligned}
$$

A relationship between individual mean wall temperatures and the piecewise uniform wall heat fluxes can be obtained by appropriate integration of (65) along the relevant boundary. In terms of mean wall temperatures, equation (58) can then be written in matrix form as

$$
\overline{\mathbf{T}}_{w}-\mathbf{T}_{m}=\frac{d_{h}}{k}\left[\mathbf{N u}_{s}^{-1}\right] \mathbf{Q}^{\prime \prime}+\frac{d_{h}^{2} q^{\prime \prime \prime}}{k} \mathbf{N u}_{v}^{-1}
$$

where

$$
\left[\mathbf{N u}_{s}^{-1}\right]=\left[\begin{array}{llll}
\left(\overline{N u}_{s, 1}^{1}\right)^{-1} & \left(\overline{N u}_{s, 2}^{1}\right)^{-1} & \left(\overline{N u}_{s, 3}^{1}\right)^{-1} & \left(\overline{N u}_{s, 4}^{1}\right)^{-1} \\
\left(\overline{N u}_{s, 1}^{2}\right)^{-1} & \left(\overline{N u}_{s, 2}^{2}\right)^{-1} & \left(\overline{N u}_{s, 3}^{2}\right)^{-1} & \left(\overline{N u}_{s, 4}^{2}\right)^{-1} \\
\left(\overline{N u}_{s, 1}^{3}\right)^{-1} & \left(\overline{N u}_{s, 2}^{3}\right)^{-1} & \left(\overline{N u}_{s, 3}^{3}\right)^{-1} & \left(\overline{N u}_{s, 4}^{3}\right)^{-1} \\
\left(\overline{N u}_{s, 1}^{4}\right)^{-1} & \left(\overline{N u}_{s, 2}^{4}\right)^{-1} & \left(\overline{N u}_{s, 3}^{4}\right)^{-1} & \left(\overline{N u}_{s, 4}^{4}\right)^{-1}
\end{array}\right]
$$

and

$$
\mathbf{N u}_{v}^{-1}=\left[\begin{array}{l}
\left(\overline{N u}_{v}^{1}\right)^{-1} \\
\left(\overline{N u}_{v}^{2}\right)^{-1} \\
\left(\overline{N u}_{v}^{3}\right)^{-1} \\
\left(\overline{N u}_{v}^{4}\right)^{-1}
\end{array}\right]
$$

where wall-mean Nusselt numbers denoted by $\overline{N u}_{s, j}^{i}$ and $\overline{N u}_{v}^{i}$ are defined as

$$
\overline{N u}_{s, j}^{2,4}=\left(\frac{1}{2 a} \int_{-a}^{a} \frac{1}{N u_{s, j}} d x\right)^{-1}, \overline{N u}_{s, j}^{1,3}=\left(\frac{1}{2 b} \int_{-b}^{b} \frac{1}{N u_{s, j}} d y\right)^{-1}
$$

$$
\overline{N u}_{v}^{2,4}=\left(\frac{1}{2 a} \int_{-a}^{a} \frac{1}{N u_{v}} d x\right)^{-1}, \overline{N u}_{v}^{1,3}=\left(\frac{1}{2 b} \int_{-b}^{b} \frac{1}{N u_{v}} d y\right)^{-1}
$$

and $\overline{N u}_{s, j}^{i}$ refer to the surface Nusselt number corresponding to the temperature difference on wall $i$ due to the heat flux on wall $j$ and the volumetric Nusselt number corresponding to wall $i$.

Due to symmetry, many of these terms are identical and in particular

$$
\begin{aligned}
\overline{N u}_{s, 1}^{1} & =\overline{N u}_{s, 3}^{3}=\overline{N u}_{s, h}^{h} \\
\overline{N u}_{s, 2}^{2} & =\overline{N u}_{s, 4}^{4}=\overline{N u}_{s, s}^{s} \\
\overline{N u}_{s, 2} & =\overline{N u}_{s, 4}^{1}=\overline{N u}_{s, 2}^{3}=\overline{N u}_{s, 4}^{3}=\overline{N u}_{s, s}^{h} \\
\overline{N u}_{s, 1}^{2} & =\overline{N u}_{s, 3}^{2}=\overline{N u}_{s, 1}^{4}=\overline{N u}_{s, 3}^{4}=\overline{N u}_{s, h}^{s} \\
\overline{N u}_{s, 3} & =\overline{N u}_{s, 1}^{3}=\overline{N u}_{s, o}^{h} \\
\overline{N u}_{s, 4}^{2} & =\overline{N u}_{s, 2}^{4}=\overline{N u}_{s, o} \\
\overline{N u}_{v} & =\overline{N u}_{v}^{3} \\
\overline{N u}_{v}^{2} & =\overline{N u}_{v}^{4}
\end{aligned}
$$

So

$$
\left[\mathbf{N u}_{s}^{-1}\right]=\left[\begin{array}{llll}
\left(\overline{N u}_{s, h}^{h}\right)^{-1} & \left(\overline{N u}_{s, s}^{h}\right)^{-1} & \left(\overline{N u}_{s, o}^{h}\right)^{-1} & \left(\overline{N u}_{s, s}^{h}\right)^{-1} \\
\left(\overline{N u}_{s, h}^{s}\right)^{-1} & \left(\overline{N u}_{s, s}^{s}\right)^{-1} & \left(\overline{N u}_{s, h}^{s}\right)^{-1} & \left(\overline{N u}_{s, o}^{s}\right)^{-1} \\
\left(\overline{N u}_{s, o}^{h}\right)^{-1} & \left(\overline{N u}_{s, s}\right)^{-1} & \left(\overline{N u}_{s, h}^{h}\right)^{-1} & \left(\overline{N u}_{s, s}^{h}\right)^{-1} \\
\left(\overline{N u}_{s, h}^{s}\right)^{-1} & \left(\overline{N u}_{s, o}^{s}\right)^{-1} & \left(\overline{N u}_{s, h}^{s}\right)^{-1} & \left(\overline{N u}_{s, s}^{s}\right)^{-1}
\end{array}\right]
$$

\section{Results and Discussion}

The following sections present some results obtained from the derivations in section 3 . The profound differences between Shercliff and Hunt flows lead, unsurprisingly, to very different heat transfer mechanisms. It is worth noting certain challenges in the computation of some of the series that arise in these solutions. There are numerous terms which are rational functions of hyperbolic functions. In particular for large $\mathrm{Ha}$, the arguments of these hyperbolic functions can be extremely large and standard double precision arithmetic is insufficient. Note that the rational functions taken as a whole are themselves finite and convergent, but computation of individual hyperbolic functions leads to out of bounds errors. This is remedied by taking logarithms of these rational functions, wherein large argument hyperbolic functions can be converted into well behaved exponentials of small arguments and subsequently exponentiated to obtain the result of any rational term.

\subsection{Shercliff Flow}

The results for the Shercliff cases are obtained by setting $P_{n}=0$ in the solutions in [8] and [10]. The heat transfer in the Shercliff flow case is determined in large part by three features which develop as $\mathrm{Ha}$ increases: Hartmann and side layers develop, of thickness $O\left(\mathrm{Ha}^{-1}\right)$ and $O\left(\mathrm{Ha}^{-0.5}\right)$ respectively, and the core flattens. It is worth pointing out that in the limit 
of large $H a$, the velocity profile increasingly exhibits the features of slug flow. The relative magnitudes of these effects are strongly dependent on the orientation and aspect ratio of the duct relative to the applied magnetic field.

\subsubsection{Uniform specified peripheral temperature $\left(H_{1}\right)$}

In the $H_{1}$ case, where the peripheral wall temperature is forced to be uniform, and the wall heat flux is allowed to vary in the peripheral direction, we obtain the peripherally mean Nusselt numbers shown in Figures 2 and 3 which graphically represent the quantities (31) and (32). Both surface and volumetric Nusselt numbers increase with increasing aspect ratio and Hartmann number. However, the heat transfer for a duct with a long Hartmann wall (perpendicular to the magnetic field) is significantly better than that for a duct with a long side-wall, at high Hartmann number, all other parameters being equal. This is to be expected, since the Hartmann wall has a significantly greater wall shear stress (and hence narrower boundary layers) at high $\mathrm{Ha}$ than the side wall and has concomitantly greater convective heat transfer. This effect contributes a greater part of the peripherally mean heat transfer for ducts with long Hartmann walls. In the limit of very large $\mathrm{Ha}$ the Nusselt numbers reach plateaux associated with slug flow.

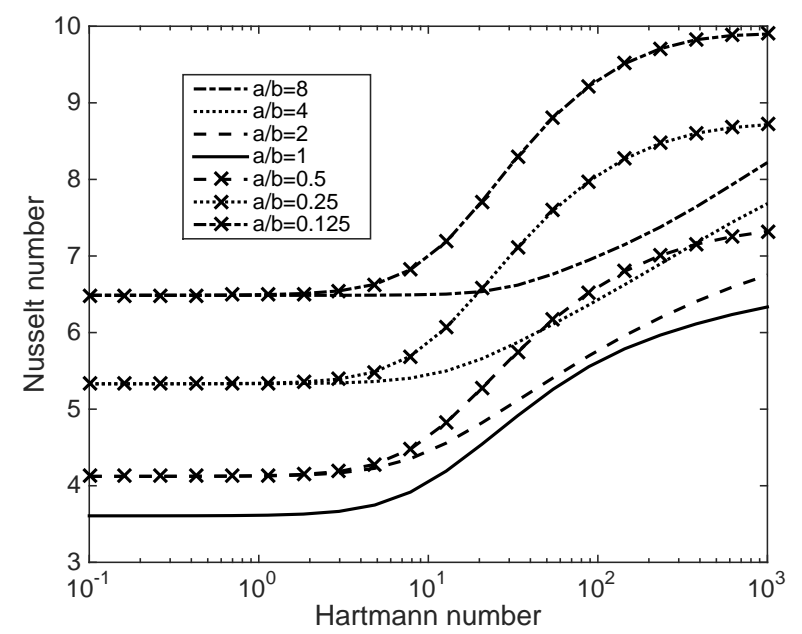

Figure 2: Peripherally mean Surface Nusselt number vs Hartmann number for various aspect ratios for the $H_{1}$ Shercliff flow case

A clearer indication of the relative effects of heat transfer at the different walls can be seen in figures 4 and 5 where the mean Nusselt numbers are obtained seperately over the Hartmann and side walls respectively and represent the quantities in (34). Figure 6 shows the ratio of side-wall to Hartmann wall Nusselt numbers $\left(\overline{N u}_{s}^{2} / \overline{N u}_{s}\right)$. As is expected, a long side wall relative to the Hartmann wall increases the ratio. For $a / b=8$ this ratio is approximately 3 for non-MHD cases, however, in the limit of large $H a$ this diminishes to about 1.5 as the greater shear stress at the Hartmann (than the side-wall) wall takes effect.

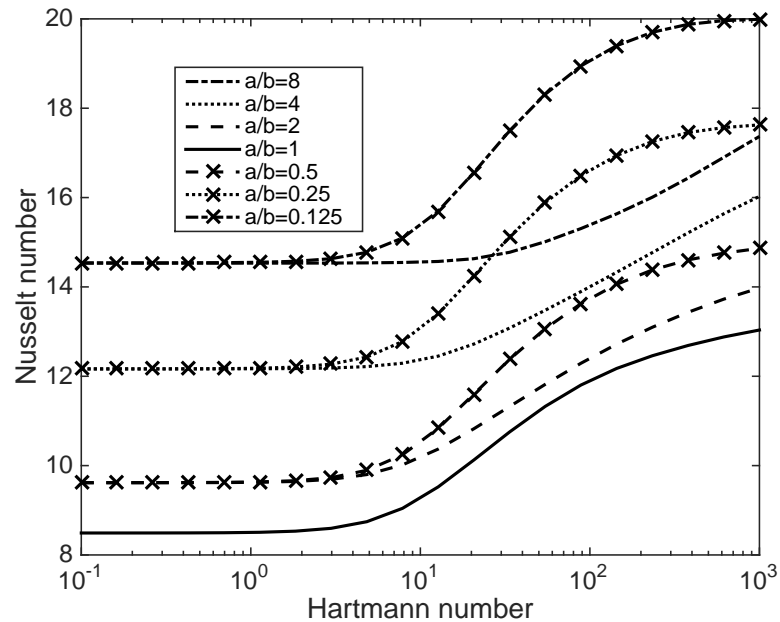

Figure 3: Peripherally mean Volume Nusselt number vs Hartmann number for various aspect ratios for the $H_{1}$ Shercliff flow case

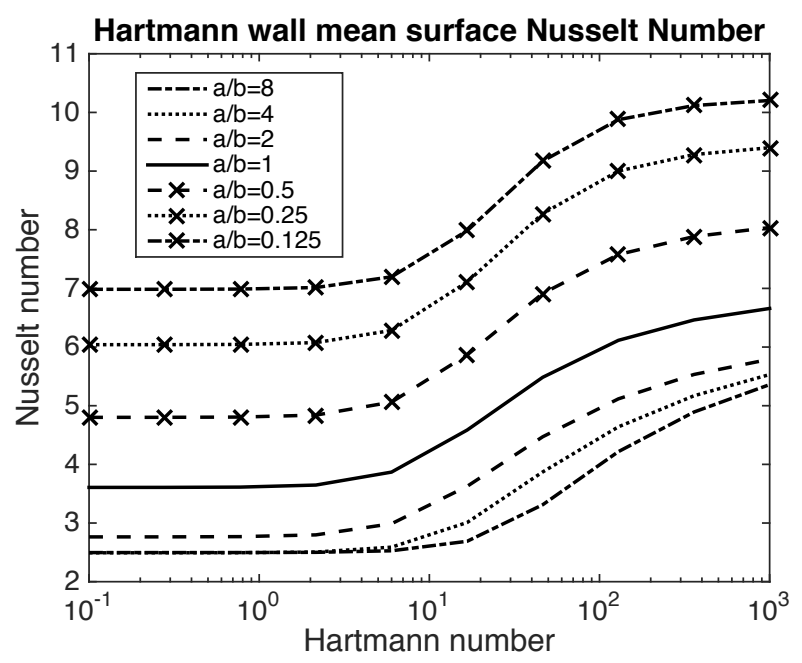

Figure 4: Hartmann wall mean Surface Nusselt number vs Hartmann number for various aspect ratios for the $H_{1}$ Shercliff flow case 


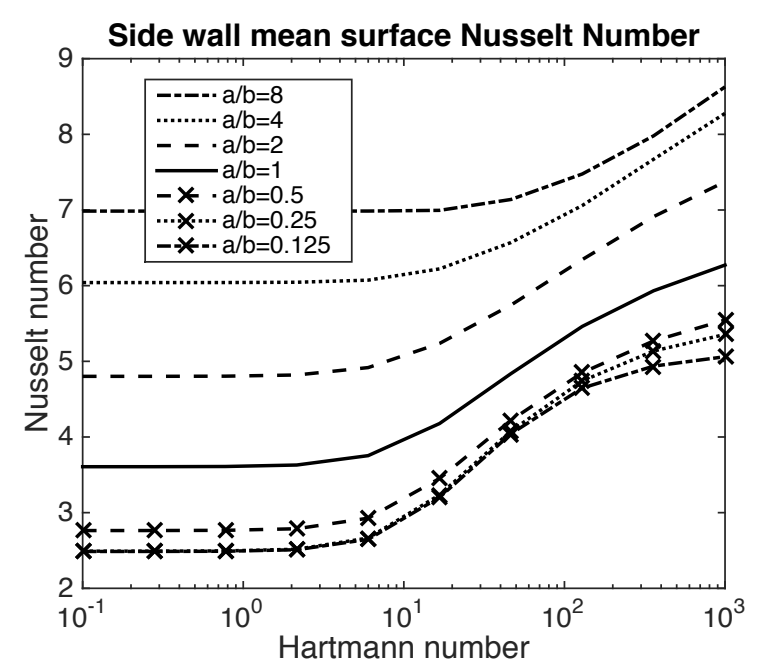

Figure 5: Side wall mean surface Nusselt number vs Hartmann number for various aspect ratios for the $H_{1}$ Shercliff flow case

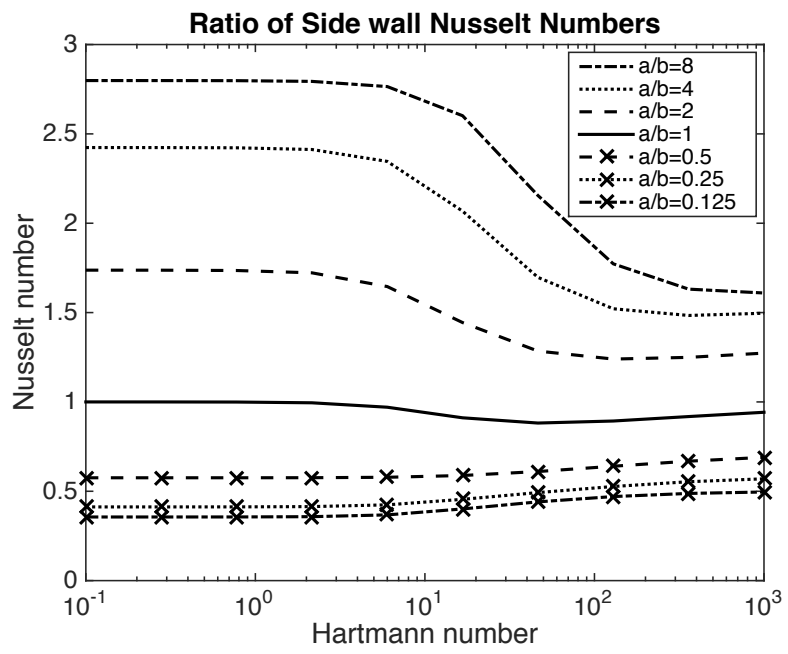

Figure 6: Ratio of side/Hartmann wall Nusselt number vs Hartmann number for various aspect ratios for the $H_{1}$ Shercliff flow case

\subsubsection{Uniform specified peripheral heat flux $\left(\mathrm{H}_{2}\right)$}

In the $\mathrm{H}_{2}$ case, where the peripheral heat flux is forced to be uniform, and the wall temperature is allowed to vary in the peripheral direction, we obtain the peripherally mean Nusselt numbers shown in Figures 7 and 8 representing (64). The Nusselt numbers are (unlike the $H_{1}$ case) only weakly dependent on aspect ratio for low $\mathrm{Ha}$ and generally exhibit an increase with increasing $\mathrm{Ha}$. For long Hartmann walls $(a / b<1)$, the Hartmann wall constitutes the greater part of the boundary and has a significantly greater wall shear stress at high $\mathrm{Ha}$ than the side wall. The contribution from the short side-wall with a lower shear stress is essentially negligible in comparison. However, for ducts with short Hartmann walls, the increase in surface Nusselt number with $\mathrm{Ha}$ is delayed and even exhibits a minimum for more extreme aspect ratios. The minimum seen in the $a / b=8$ case is explained by the evolution of the flow in Figure 9. For $H a=0.1$, the $Y$-dependence of the velocity is uniform over much of the width of the duct, only reducing very near to the short Hartmann walls. For $\mathrm{Ha}=20.0$ the flow is now being suppressed at the extremes of the duct, both counteracting the nominally increased shear stress on the short Hartmann walls and, due to the thin aspect ratio, reducing heat transfer from the far ends of the side walls. As a result, the peripheral mean Nusselt number is reduced relative to the $H a=0.1$ case. Beyond $\mathrm{Ha}=20$, the narrowing side-wall layer develops, aiding heat transfer and the core flow flattens. Of particular note is the very large volumetric Nusselt numbers obtained for large $\mathrm{Ha}$ in this $\mathrm{H}_{2}$ case (figure 8) - a result of the fact that in the limit of large $H a$ the flow approaches slug flow (in effect the volumetric heating has no impact on the temperature profile) as explained in section 3.1.

These effects are seen clearly in Figures 10 and 11 where the separate mean surface Nusselt numbers associated with the Hartmann and side walls respectively, are shown. In these cases the contribution of the shorter Hartmann walls, with high shear stresses, is reduced as the aspect ratio increases.

\subsubsection{Non-uniform specified peripheral heat flux $\left(n u H_{2}\right)$}

For the non-uniform $\mathrm{nuH}_{2}$ case with Shercliff flow, we obtain the reciprocals of the Nusselt coefficients shown in Figure 12 which appear in equations (67) and (73). The reason for presenting reciprocals here is simply clarity: These Nusselt numbers can become infinite in certain scenarios and it is then much clearer to consider the non-dimensional temperature (which is the reciprocal of $\mathrm{Nu}$ ). A useful interpretation of these results is to consider scenarios where a single wall (side or Hartmann) is heated whilst the remaining walls are adiabatic. Figures 12(a), (c) and (e) then represent the non-dimensional temperature difference at the heated Hartmann wall (a), the adjacent adiabatic sides walls (c) and the remaining adiabatic Hartmann wall (e). Figures 12(b), (d) and (f) represent the non-dimensional temperature difference at a heated side wall (b), the adiabatic Hartmann walls (d) and the remaining adiabatic side wall (f).

High temperatures occur, as expected, at the heated wall, shown in Figures $12(a, b)$ and the highest temperatures are seen for the shortest heated walls which is due to significant corner effects where flow is suppressed. These temperatures reduce 


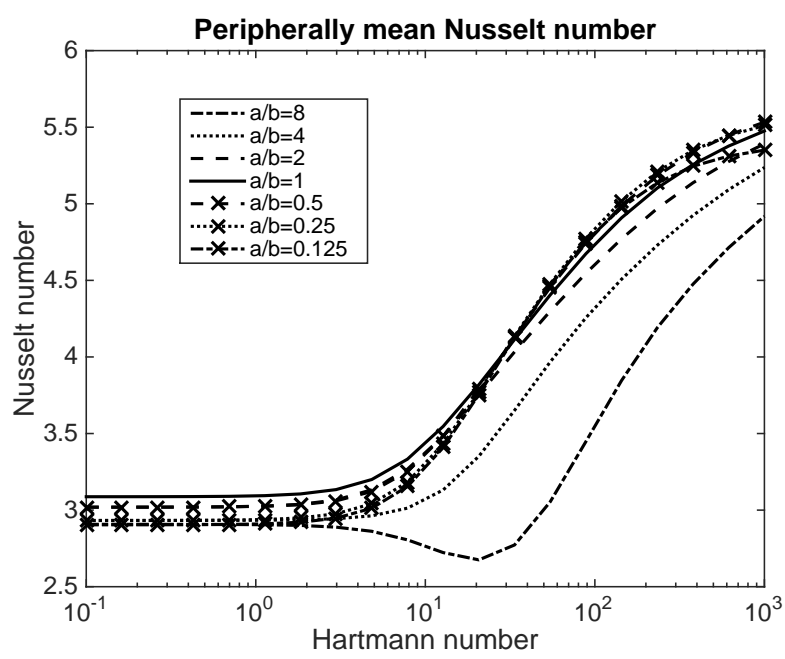

Figure 7: Peripherally mean Surface Nusselt number vs Hartmann number for various aspect ratios for the $\mathrm{H}_{2}$ Shercliff flow case

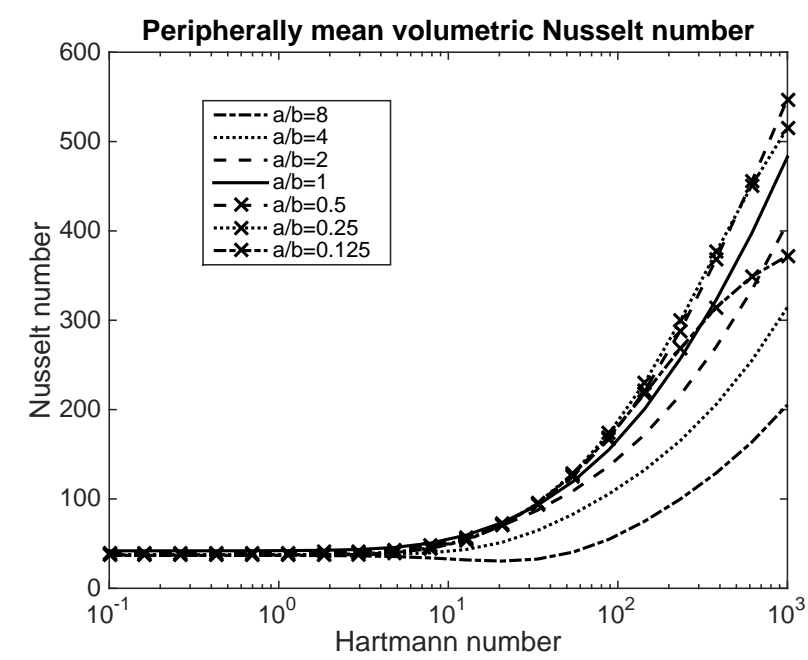

Figure 8: Peripherally mean Volume Nusselt number vs Hartmann number for various aspect ratios for the $\mathrm{H}_{2}$ Shercliff flow case

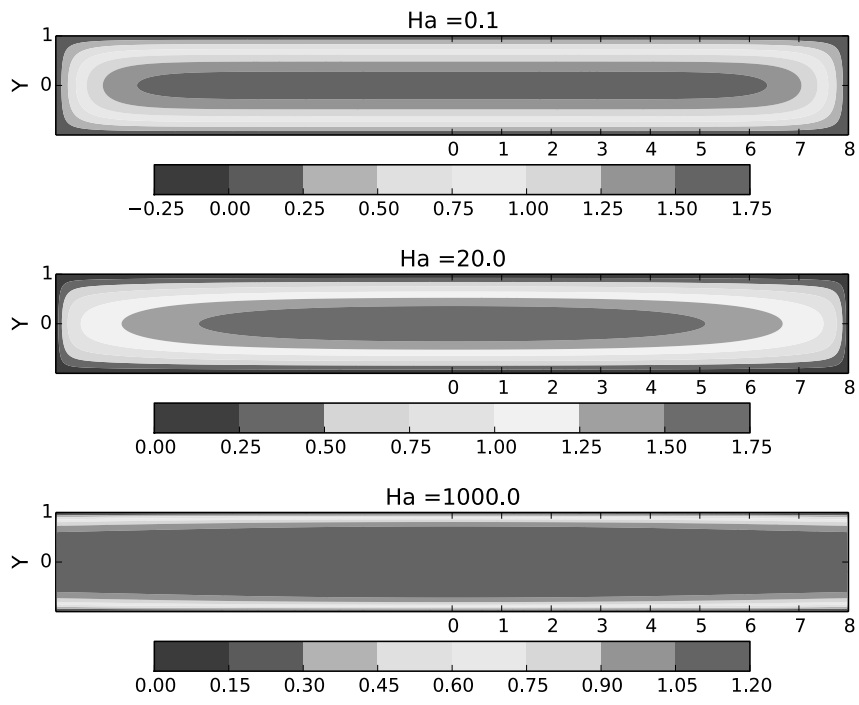

Figure 9: Evolution of the non-dimensional velocity in the Shercliff flow case for $a / b=8$

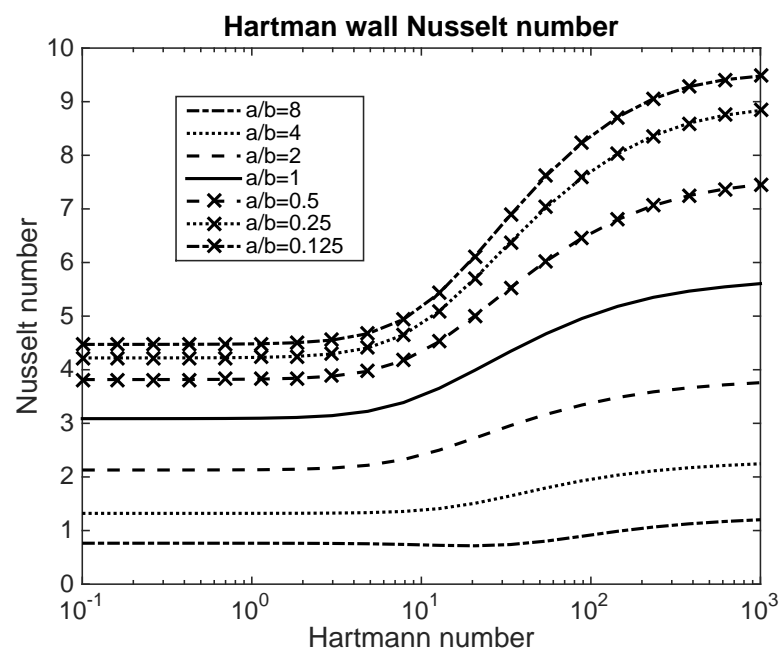

Figure 10: Hartmann wall mean surface Nusselt number vs Hartmann number for various aspect ratios for the $\mathrm{H}_{2}$ Shercliff flow case 


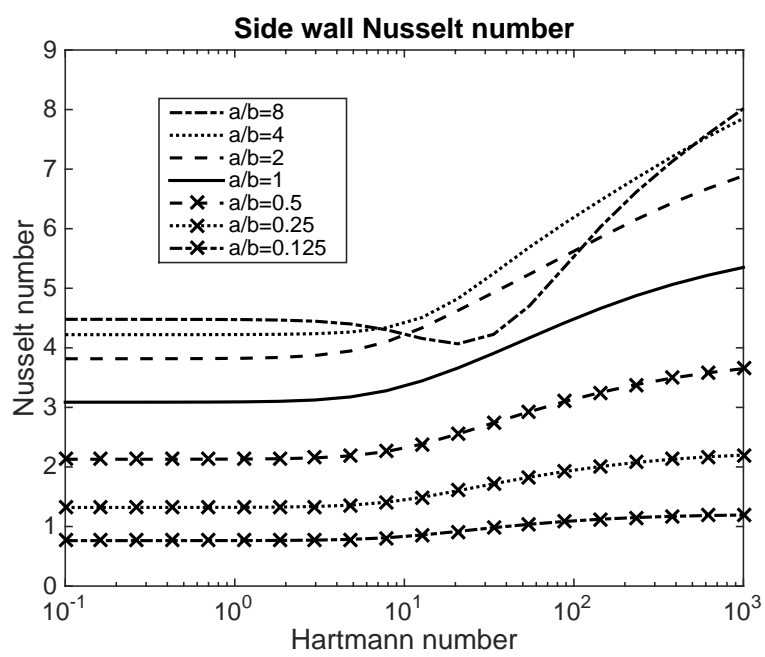

Figure 11: Side-wall mean surface Nusselt number vs Hartmann number for various aspect ratios for the $\mathrm{H}_{2}$ Shercliff flow case

progressively for the longer heated sides. These heated wall temperatures exhibit a modest reduction with increasing $\mathrm{Ha}$ as the shear stresses increase in the narrowing layer of the heated wall.

Lower temperatures are seen on adjacent walls (to the heated wall) (Figures $12(\mathrm{c}, \mathrm{d})$ ). The highest adjacent wall temperatures are seen for cases with short adjacent walls (long heated walls) and are comparable to the temperature on the long heated walls. Equivalently, lower adjacent wall temperatures are seen for longer adjacent walls. There is a significant reduction in adjacent wall temperature as $\mathrm{Ha}$ increases as the shear stresses increase near the adjacent wall. Indeed the temperature is almost negligible in the case of a short heated wall with a long adjacent wall. The exception to this is Figures 12(d) for the extreme $a / b=8$ case. This is due to the initial flow suppression near the corners around $H a=20$, prior to subsequent enhancement due to the narrowing of the Hartmann layer beyond $\mathrm{Ha}=20$ seen in Figures 9.

Subcooling, where the wall temperature is below the bulk temperature, is seen on the opposing walls (Figures $12(\mathrm{e}, \mathrm{f})$ ). This is most extreme for short heated/opposing walls. 
(a) $1 / \mathrm{Nu}_{\mathrm{s}, \mathrm{h}}^{\mathrm{h}}$

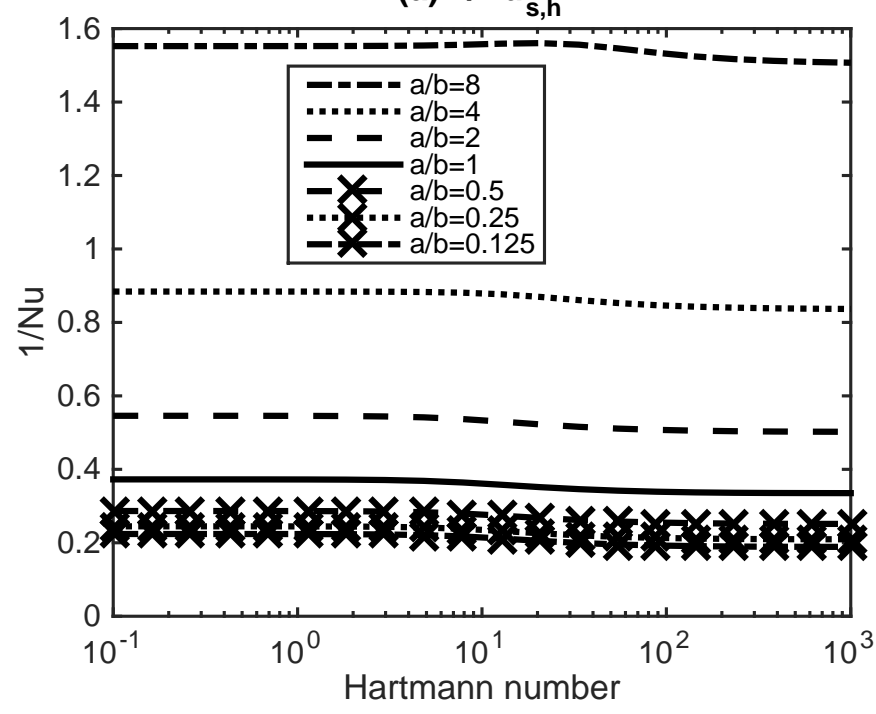

(c) $1 / \mathrm{Nu}_{s, \mathrm{~h}}^{\mathrm{s}}$

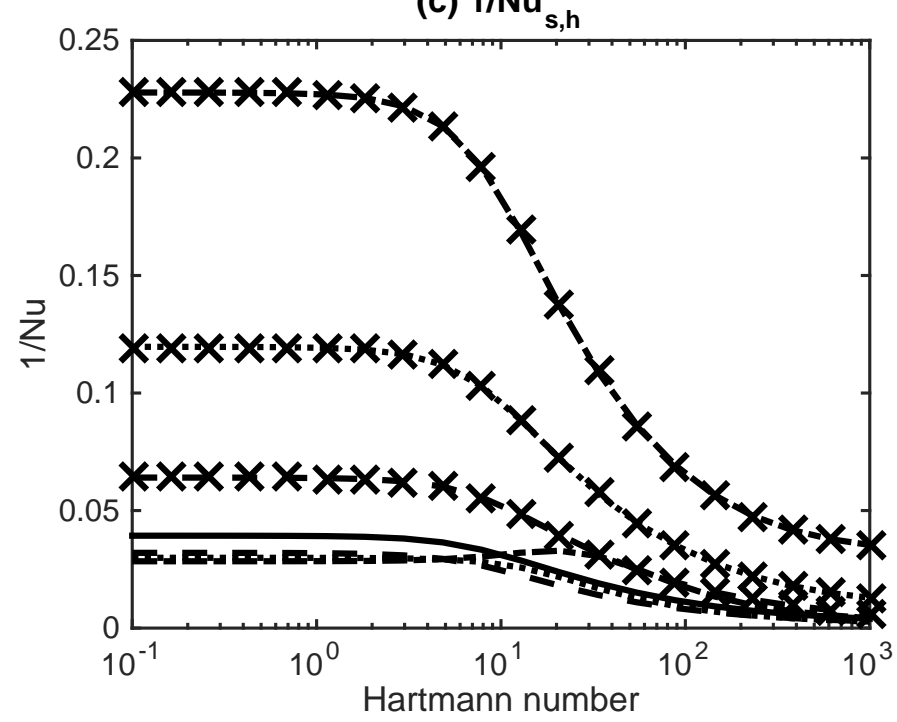

(e) $1 / \mathrm{Nu}_{s, h}^{\circ}$

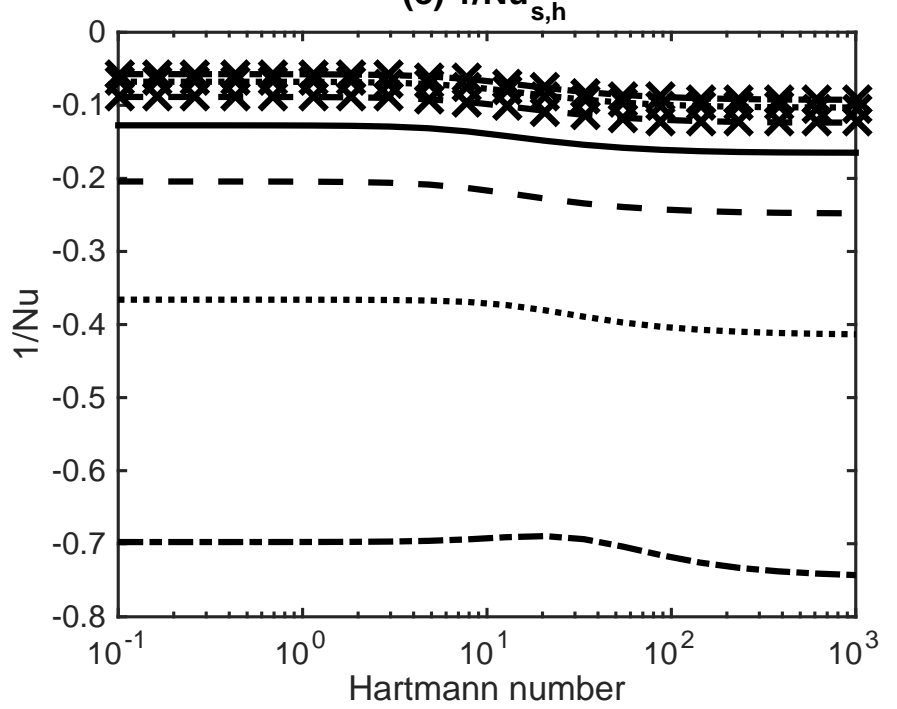

(b) $1 / \mathrm{Nu}_{\mathrm{s}, \mathrm{s}}^{\mathrm{s}}$

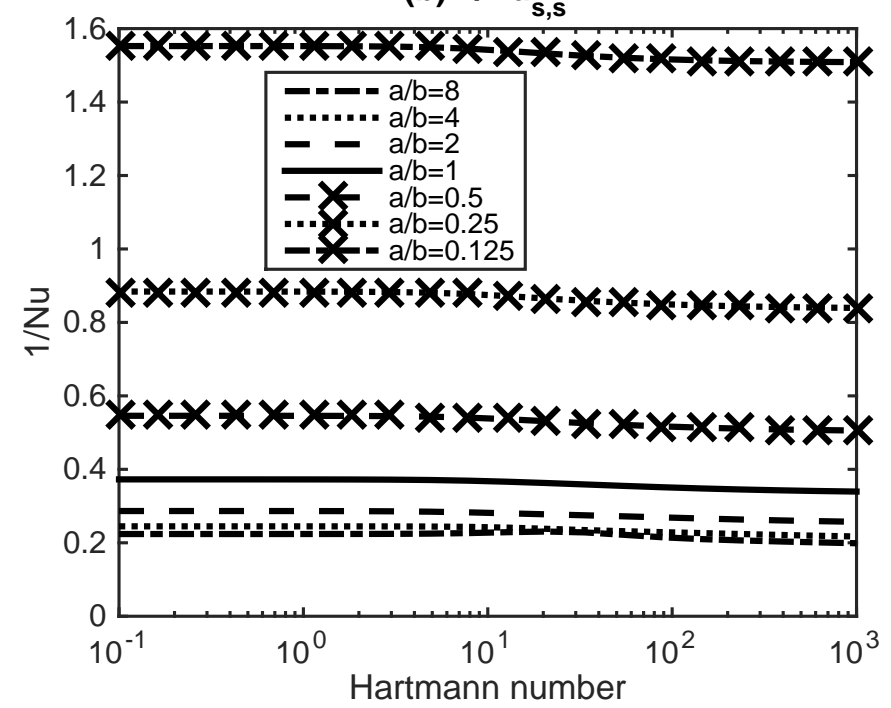

(d) $1 / \mathrm{Nu}_{\mathrm{s}, \mathrm{s}}^{\mathrm{h}}$

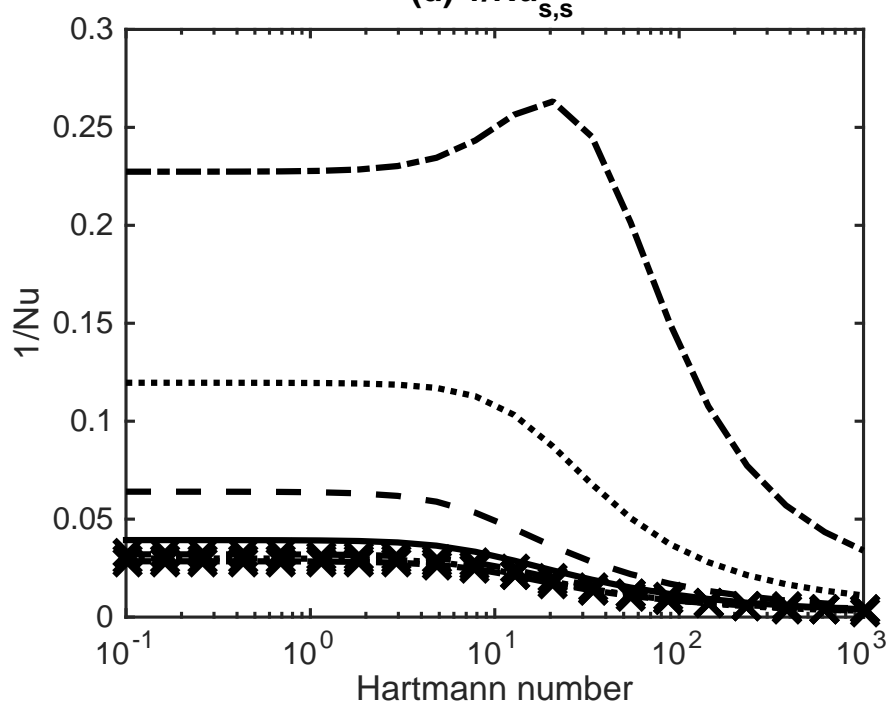

(f) $1 / \mathrm{Nu}_{\mathrm{s}, \mathrm{s}}^{\circ}$

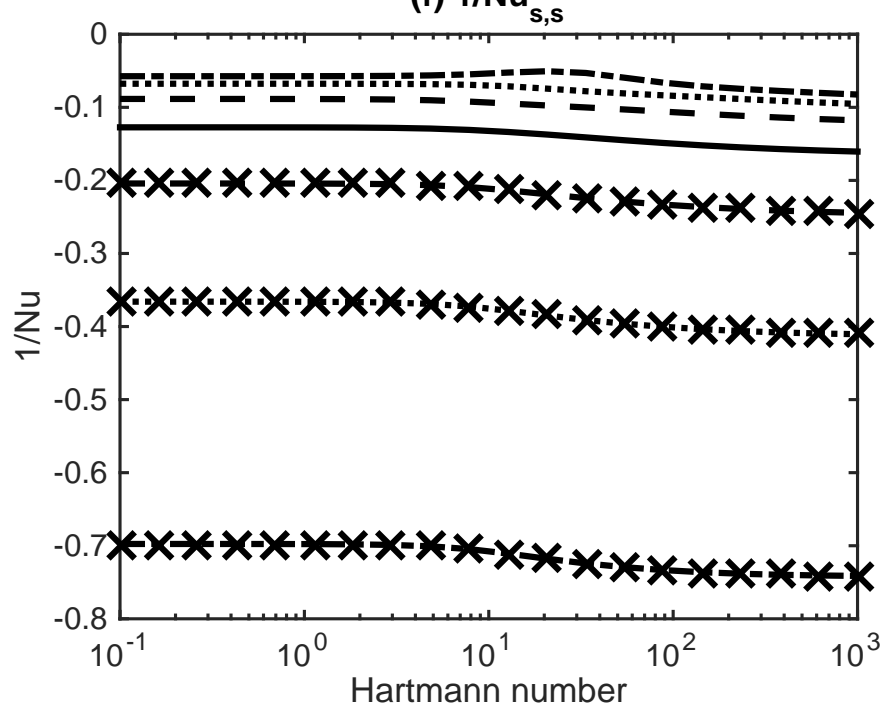

Figure 12: Nusselt numbers vs Hartmann number for various aspect ratios for the $\mathrm{H}_{2}$ Shercliff flow case 


\subsection{Hunt-II Flow}

The Hunt-II flow case presents additional complexity over and above that of Shercliff flow. There are now four features that develop with increasing $\mathrm{Ha}$ : As with the Shercliff flow, the Hartmann and side layers narrow, however the core flow not only flattens but is also suppressed (almost to the point of stagnation) and is accompanied by the evolution of jets in proximity to the side walls. One implication of the core suppression is that the effect of the Hartmann layer, which plays such an important role in enhancing heat transfer near the wall for Shercliff flows, is itself suppressed due to the reduction in flow rate near the wall. The onset and magnitudes of these effects are strongly dependent on the aspect ratio and orientation relative to the applied magnetic field.

In the following sections we consider a non dimensional Hartmann wall thickness $\delta=0.05$, irrespective of aspect ratio, and conductivity ratio $\sigma_{f} / \sigma_{w}=1$.

\subsubsection{Uniform specified peripheral temperature $\left(H_{1}\right)$}

In the $H_{1}$ case for Hunt-II flow, we obtain the peripherally mean Nusselt numbers shown in Figures 13 and 14. The Nusselt numbers increase with increasing aspect ratio and Hartmann number, as they do in Shercliff flow, for $\mathrm{Ha}<100$. However, for $\mathrm{Ha}>100$, the heat transfer for a duct with a long Hartmann wall is significantly worse than that for a duct with a long side-wall, unlike the Shercliff case (see Figures 2 and 3). Of particular note is the observation that long side-wall cases exhibit an exponential increase in $\mathrm{Nu}$ with $\mathrm{Ha}$, at least in this parameter range and that there is an optimal aspect ratio close to $a / b=4$. This behaviour is principally due to the development of cooling jets parallel to the side walls with increasing $H a$. These jets lead to greatly increased heat flux at the side walls. Heat transfer due to the narrow Hartmann layer (which dominates the heat transfer in Shercliff flow), is comparatively modest in this scenario.

The relative effects of heat transfer at the different walls can be seen in figures 15,16 . Figure 17 shows the ratio of side-wall to Hartmann wall Nusselt numbers $\left(\overline{N u}_{s}^{2} / \overline{N u}_{s}^{1}\right)$. As is the case in Shercliff flow, a long side wall relative to the Hartmann wall increases the ratio. As before, for $a / b=8$ this ratio is approximately 3 for non-MHD cases, however, unlike the Shercliff case, in the limit of large $\mathrm{Ha}$ this increases to approximately 5 as the side-wall jets develop.

\subsubsection{Uniform specified peripheral heat flux $\left(\mathrm{H}_{2}\right)$}

In the $\mathrm{H}_{2}$ case for Hunt-II flow, the peripherally mean Nusselt numbers are shown in Figures 18 and 19. Optimal wall heat transfer for high $\mathrm{Ha}$ occurs for $a / b \approx 0.25$. Figure 20 shows the surface heat flux-driven component of the non-dimensional temperature for a square duct at low and high $\mathrm{Ha}$. The cooling effect of the jets at high $\mathrm{Ha}$ is clear. This cooling is sufficient to lead to subcooling where singularities and negative values of the pointwise Nusselt numbers are obtained at some points on the wall and in Figure 19 the reciprocal of the peripherally mean volumetric Nusselt number is plotted (rather than $\mathrm{Nu}$ ) for clarity. These effects are exhibited for all aspect ratios, with the

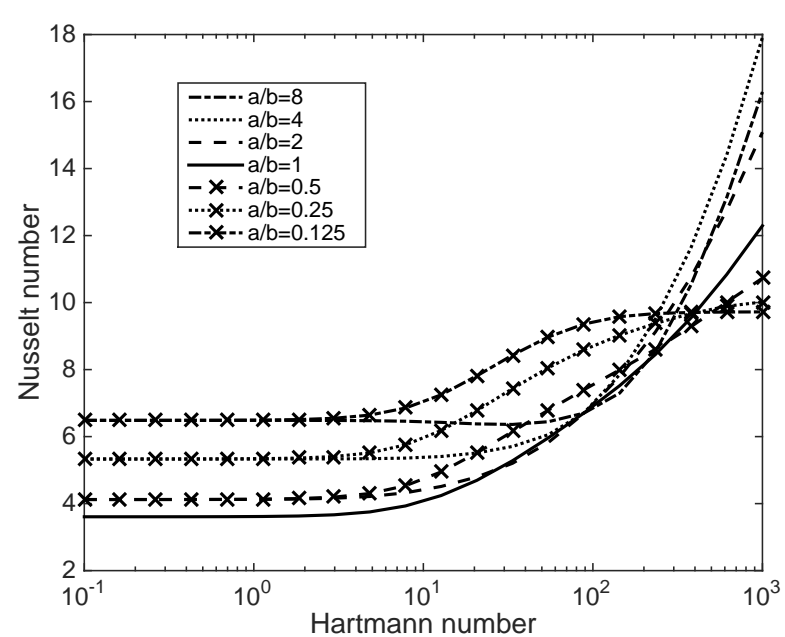

Figure 13: Peripherally mean Surface Nusselt number vs Hartmann number for various aspect ratios for the $H_{1}$ Hunt-II flow case

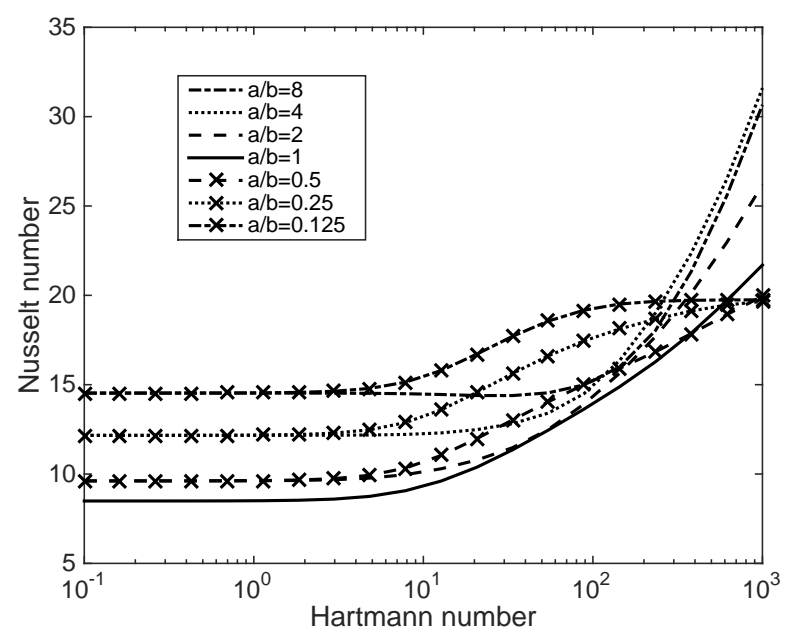

Figure 14: Peripherally mean Volume Nusselt number vs Hartmann number for various aspect ratios for the $H_{1}$ Hunt-II flow case 


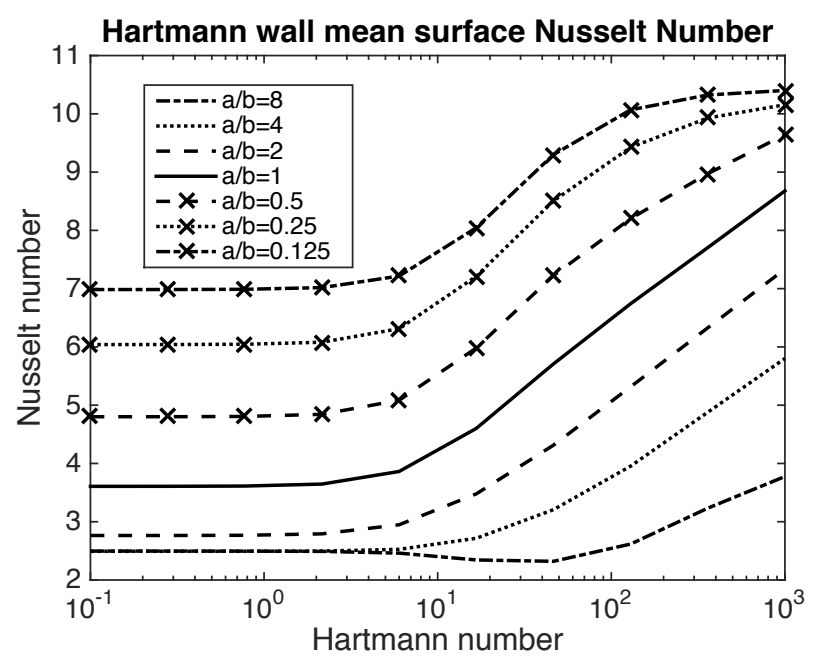

Figure 15: Hartmann wall mean Surface Nusselt number vs Hartmann number for various aspect ratios for the $H_{1}$ Hunt-II flow case

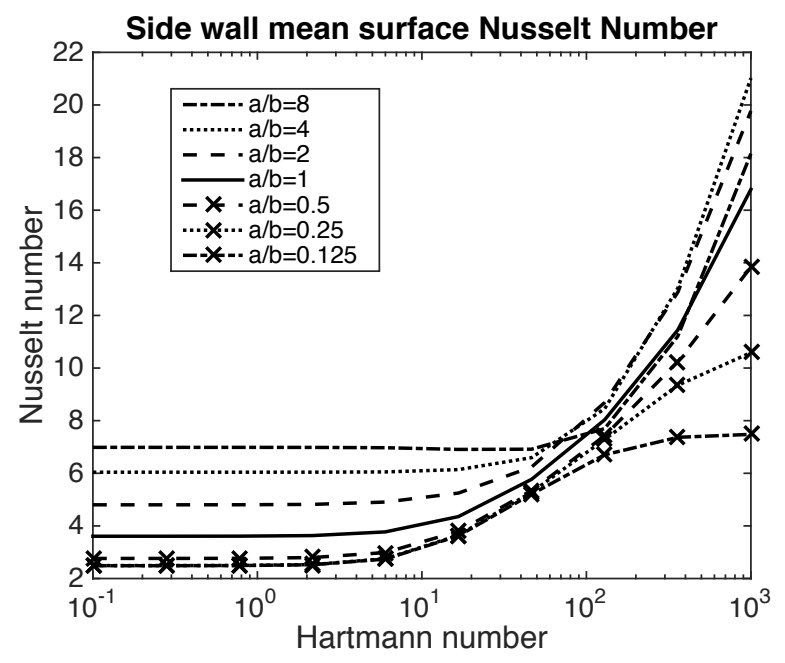

Figure 16: Side wall mean surface Nusselt number vs Hartmann number for various aspect ratios for the $H_{1}$ Hunt-II flow case

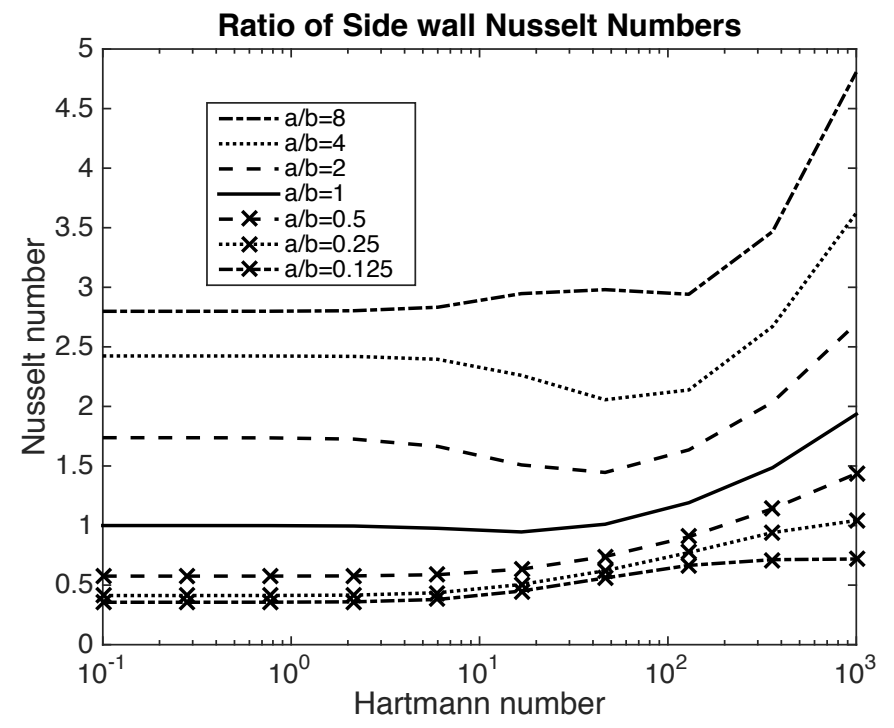

Figure 17: Ratio of side/Hartmann wall Nusselt number vs Hartmann number for various aspect ratios for the $H_{1}$ Hunt-II flow case

notable exception of $a / b=8$, explained with the aid of Figure 21. For $H a=0.1$, the $Y$-dependence of the velocity is uniform over much of the width of the duct, only reducing very near to the short Hartmann walls. For $H a=20.0$ the flow is now being suppressed at the extremes of the duct, both counteracting the nominally increased shear stress on the short Hartmann walls and, due to the thin aspect ratio, reducing heat transfer from far ends of the side walls. As a result, the peripheral mean Nusselt number is reduced relative to the $H a=0.1$ case. Beyond $H a=20$, the distinct side-wall jets develop and the core flow approaches stagnation. For this aspect ratio, the heat transfer is dominated by the effective side-wall jet cooling and, despite the poor Hartmann wall heat transfer, the peripheral mean heat transfer improves with increasing $\mathrm{Ha}>20$.

As in section 4.1.2, it is useful to consider the separate wallaveraged Nusselt numbers. These are shown in Figures 22 and 23. In general, as $\mathrm{Ha}$ increases, both side and Hartmann wall temperatures reduce as the heat transfer improves, similar to the Shercliff case. There are two notable exceptions to this, due to the flow features explained above: Firstly, for aspect ratios with very long side walls (eg. $a / b=8$ ), heat transfer deteriorates with increasing $\mathrm{Ha}$ on much of the side-wall and all of the Hartmann wall. Secondly, at the Hartmann wall, the heat transfer reaches a maximum, and thereafter reduces with increasing $H a$. These are due to the competing effects of side jets and core suppression. At the side walls, the development of jets aids heat transfer, but this development is delayed for large $a / b$; jets cannot form until the side layer thickness is significantly less than $b$. Correspondingly, core suppression, which in the case of Hunt flow ultimately approaches stagnation and inhibits heat transfer at the Hartmann walls, develops as $\mathrm{Ha}$ increases, but more slowly for smaller $a / b$. 


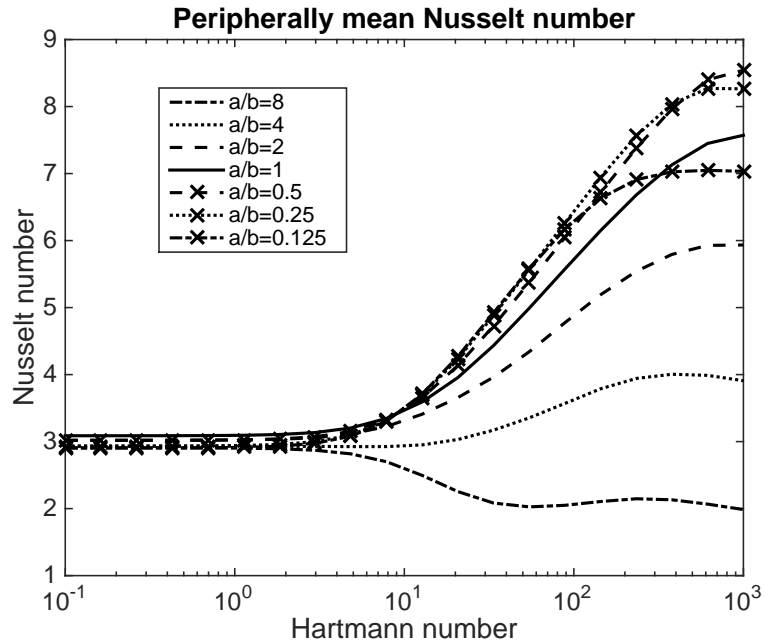

Figure 18: Peripherally mean Surface Nusselt number vs Hartmann number for various aspect ratios for the $\mathrm{H}_{2}$ Hunt-II flow case

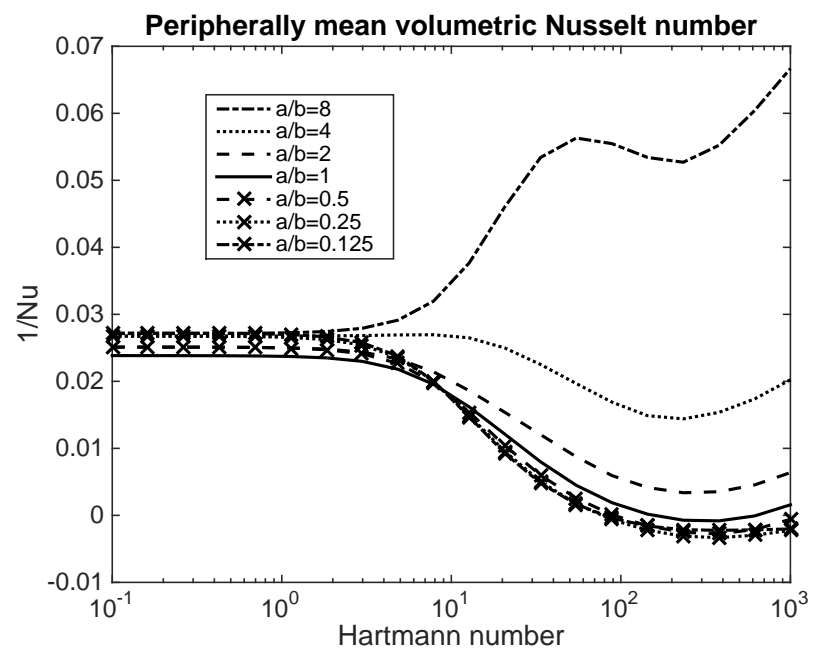

Figure 19: Peripherally mean Volumetric Nusselt number vs Hartmann number for various aspect ratios for the $\mathrm{H}_{2}$ Hunt-II flow case
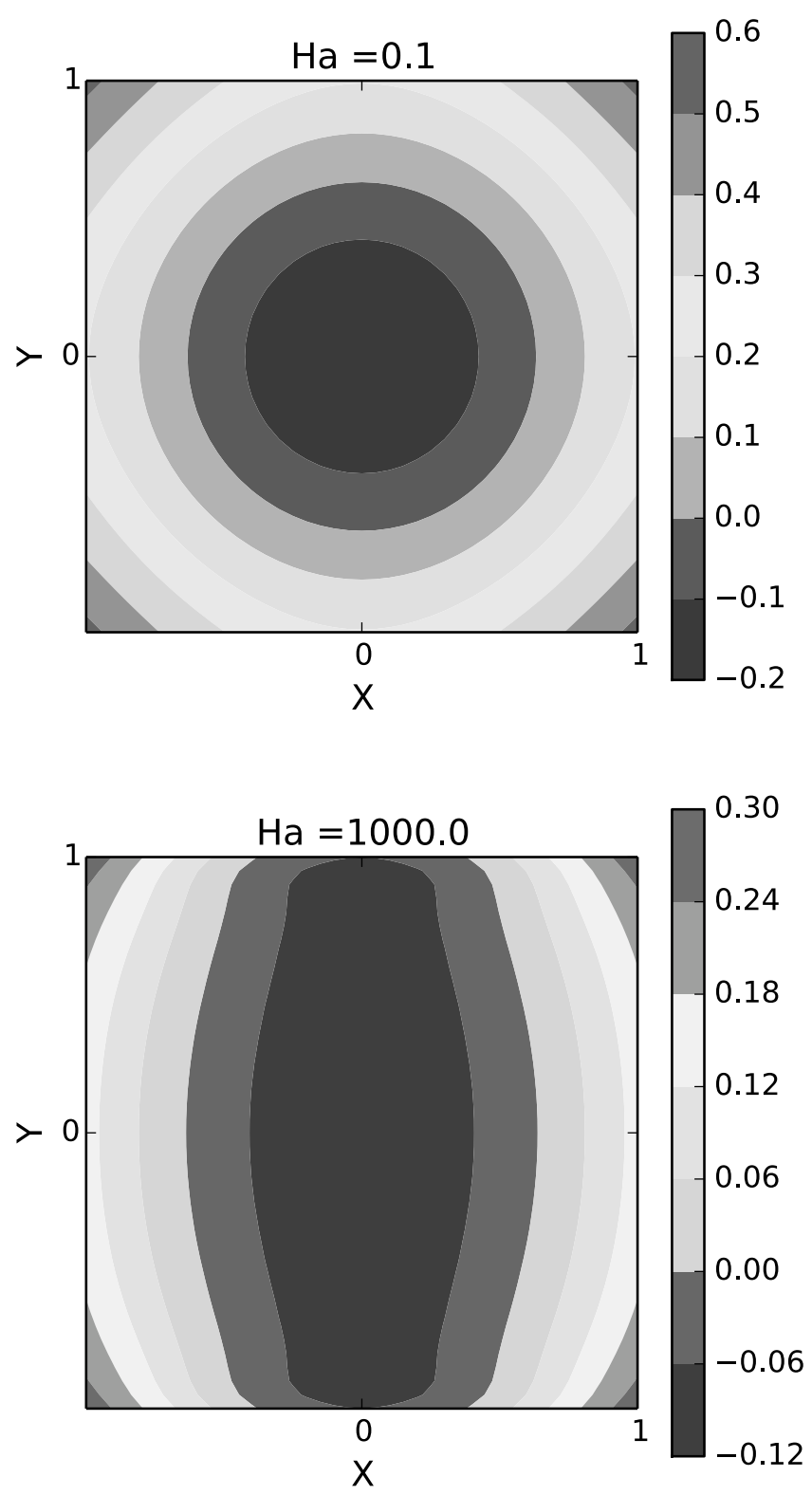

Figure 20: Non-dimensional temperature profile $1 / N u_{s}$ for $a / b=1$ due to $H_{2}$ 

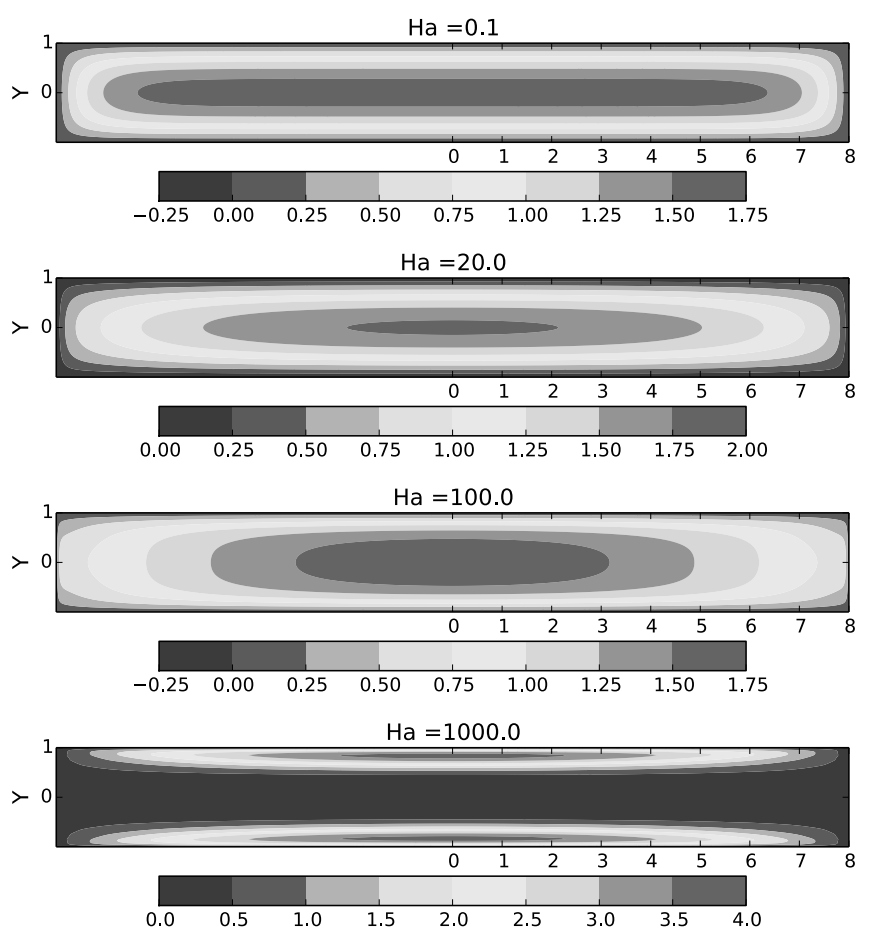

Figure 21: Evolution of the non-dimensional velocity in the Hunt-II flow case for $a / b=8$

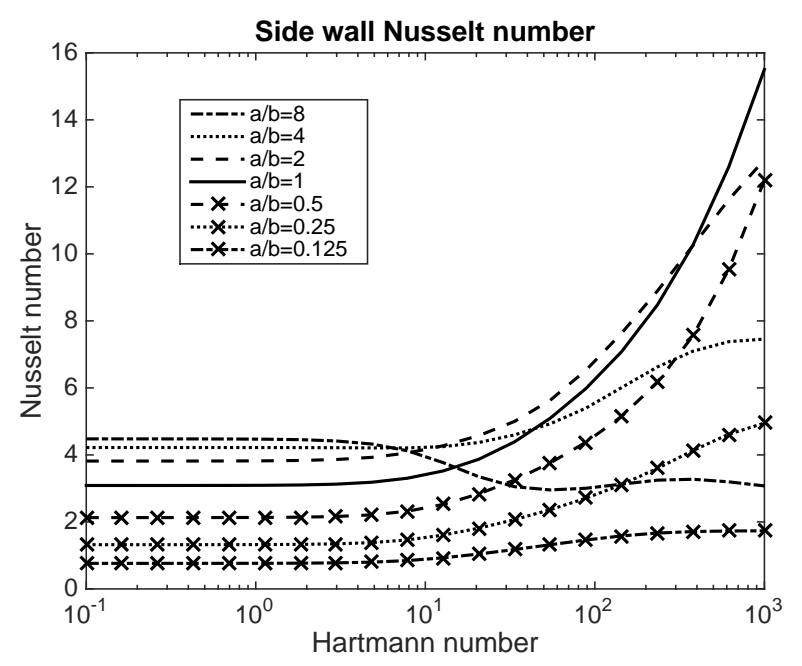

Figure 22: Side-wall mean surface Nusselt number vs Hartmann number for various aspect ratios for the $\mathrm{H}_{2}$ Hunt-II flow case

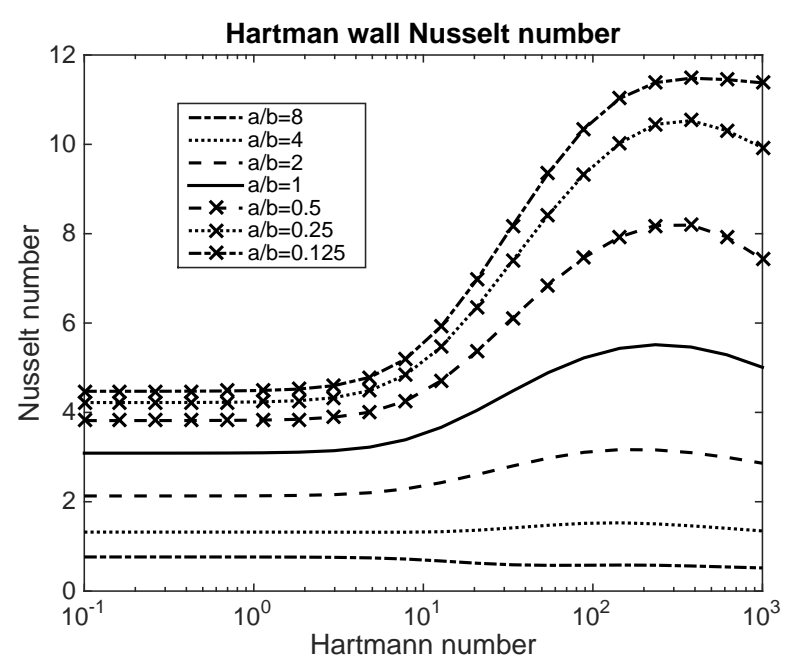

Figure 23: Hartmann wall mean surface Nusselt number vs Hartmann number for various aspect ratios for the $\mathrm{H}_{2}$ Hunt-II flow case

\subsubsection{Non-uniform specified peripheral heat flux $\left(\mathrm{nuH}_{2}\right)$}

For the non-uniform $\mathrm{H}_{2}$ case with Hunt flow, we obtain the reciprocals of the Nusselt coefficients shown in Figure 24 which appear in equations (67) and (73). As in section 4.1.3, it is useful to consider scenarios where a single wall (side or Hartmann) is heated whilst the remaining walls are adiabatic. Figures 24(a), (c) and (e) represent the non-dimensional temperature difference at the heated Hartmann wall (a), the adjacent adiabatic sides walls (c) and the remaining adiabatic Hartmann wall (e). Figures 24(b), (d) and (f) represent the non-dimensional temperature difference at a heated side wall (b), the adiabatic Hartmann walls (d) and the remaining adiabatic side wall (f).

As in the Shercliff case, high temperatures occur, as expected, at the heated wall, shown in Figures $24(a, b)$. Again, the highest temperatures are seen on short heated sides and reduce progressively for the longer heated sides. These heated wall temperatures exhibit a small reduction with increasing $\mathrm{Ha}$.

Lower temperatures are seen on adjacent walls (to the heated wall) (Figures $24(\mathrm{c}, \mathrm{d})$ ). For low $\mathrm{Ha}$, the highest adjacent wall temperatures are obtained for short adjacent walls and are comparable to the temperature on the long heated walls. Correspondingly lower wall temperatures are seen for longer adjacent walls. Again, as with the Shercliff case, there is a significant reduction in adjacent wall temperature as $\mathrm{Ha}$ increases and for large $\mathrm{Ha}$ sub-cooling can occur for adjacent walls. This is most notable in the intermediate $(0.125<a / b \leq 1)$ longer heated Hartmann wall case (c) and in the short heated side wall cases in (d) where in both cases side jet cooling assists in heat removal. The exception to this occurs for $a / b=8$ in Figures 24(c,d). The reason for this is seen with reference to Figure 21. For $H a \approx 20$, the flow at the extreme ends is suppressed, elevating the temperatures on the short Hartmann walls. By $H a \approx 100$ the Hartmann layers have narrowed, and the resulting increased shear stresses lead to reduction in wall temperature. Beyond 
this the core stagnates, nullifying the improved Hartmann wall heat transfer, and leads to an increase in wall temperature.

Similar to the Shercliff case, sub-cooling is seen on the opposing walls (Figures 24 (e,f)). This is most extreme for short opposing walls. The sub-cooling generally increases with increasing $\mathrm{Ha}$ for the heated side wall case (f). An exception is the case of the longest heated side wall cases $(a / b=8)$. For the heated Hartmann wall case, sub-cooling increases between $0<H a<100$ and decreases thereafter. Again, we have an exception for the $a / b=8$ case where sub-cooling reduces more or less monotonically. 
(a) $1 / \mathrm{Nu}_{\mathrm{s}, \mathrm{h}}^{\mathrm{h}}$

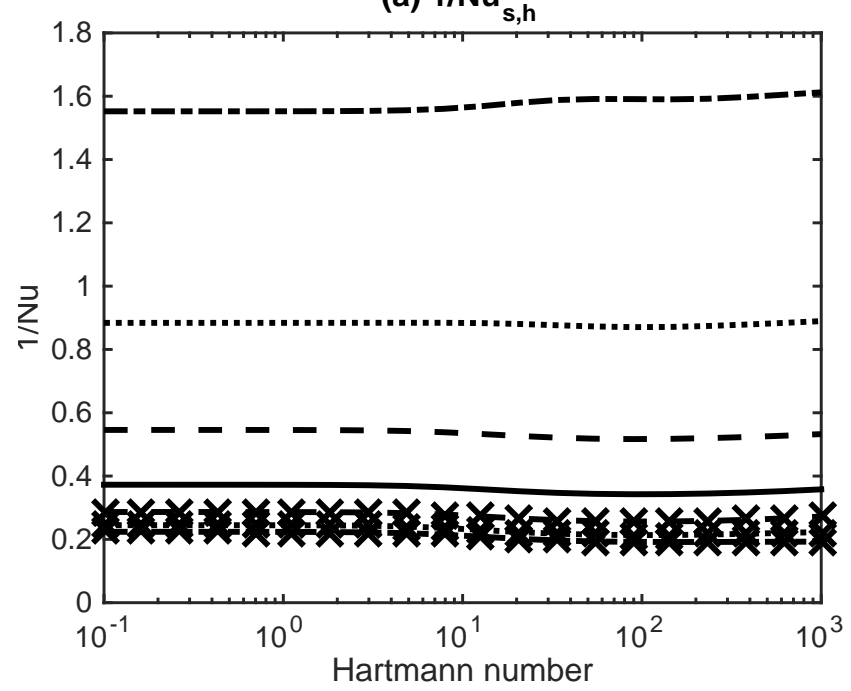

(c) $1 / \mathrm{Nu}_{\mathrm{s}, \mathrm{h}}^{\mathrm{s}}$

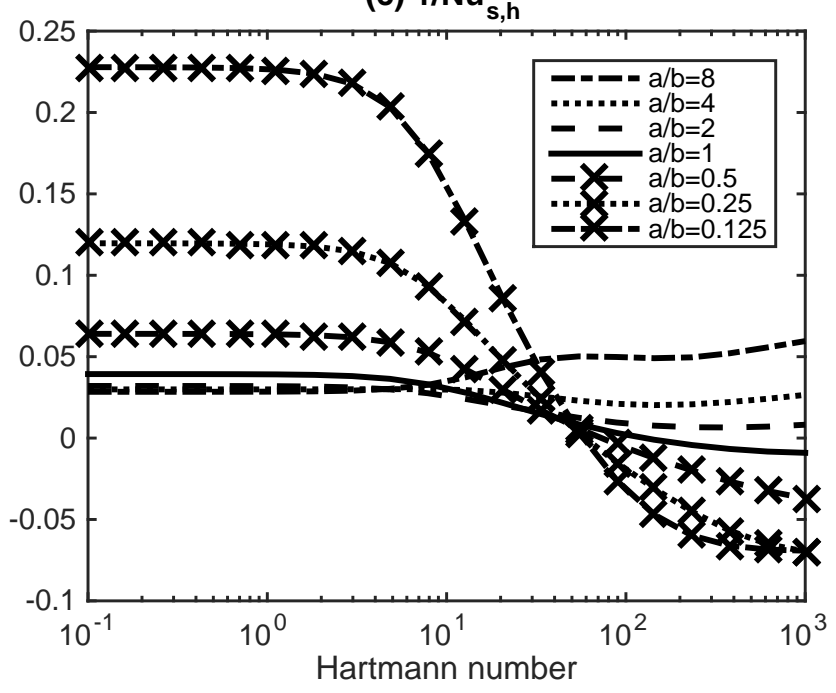

(e) $1 / \mathrm{Nu}_{s, h}^{\circ}$

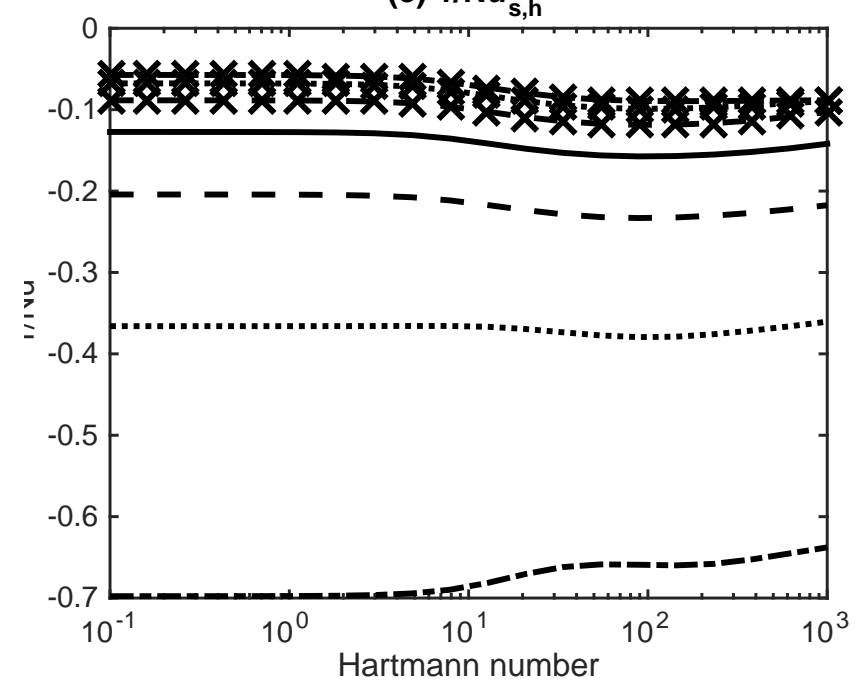

(b) $1 / \mathrm{Nu}_{\mathrm{s}, \mathrm{s}}^{\mathrm{s}}$

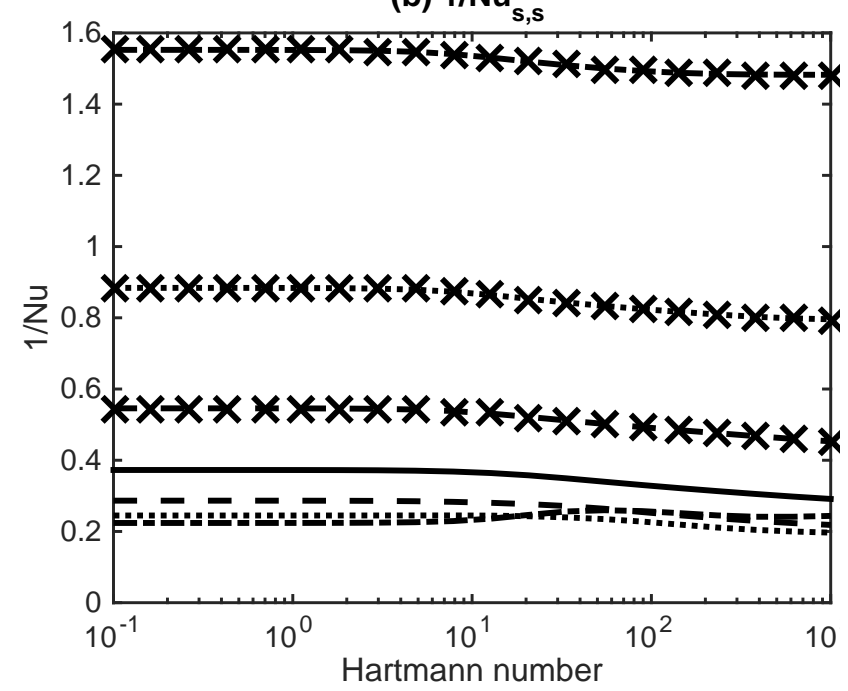

(d) $1 / \mathrm{Nu}_{\mathrm{s}, \mathrm{s}}^{\mathrm{h}}$

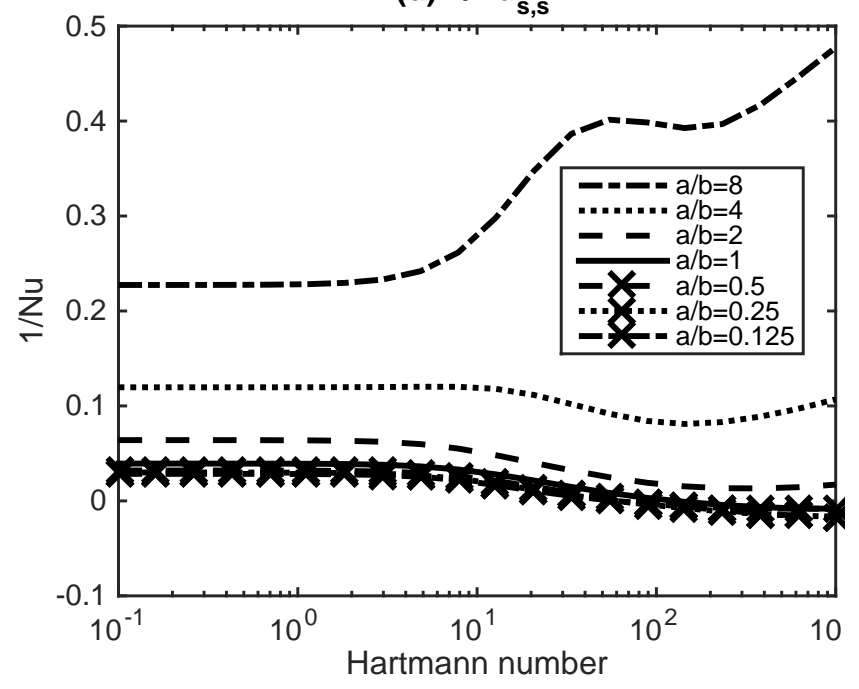

(f) $1 / \mathrm{Nu}_{\mathrm{s}, \mathrm{s}}^{\circ}$

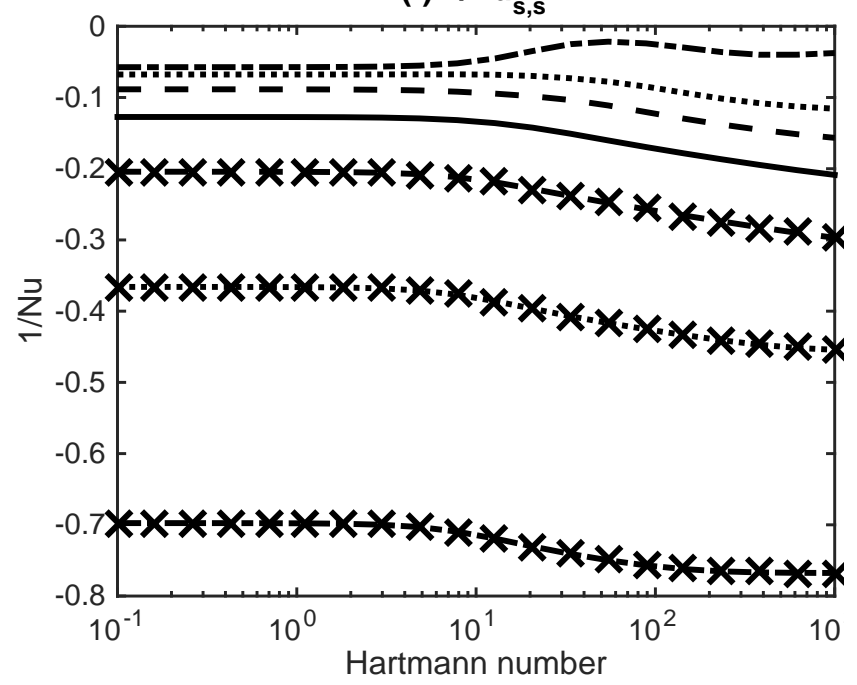

Figure 24: Nusselt numbers vs Hartmann number for various aspect ratios for the $\mathrm{H}_{2}$ Hunt-II flow case 


\section{Conclusions}

The heat transfer problem for MHD flow subject to nonuniform wall heat flux and uniform volumetric heating in rectangular ducts with electrically insulated and partially conducting thick walls subject to a transverse magnetic field is solved analytically for both $H_{1}$ and $H_{2}$ heat transfer cases. These results will enable engineers to produce optimal duct configurations for the flows unique to magnetohydrodynamics. Notable features of the heat transfer can be summarized as:

\subsection{Shercliff Flow}

- Heat transfer in all cases is determined by the very different boundary layer thicknesses near Hartmann $\left(\mathrm{O}\left(\mathrm{Ha}^{-1}\right)\right)$ and side $\left(O\left(H a^{-0.5}\right)\right)$ walls. The narrower Hartmann layer yields higher wall shear stress and enhanced heat transfer.

- Increasing the magnetic field enhances both peripherally mean $H_{1}$ surface and volume Nusselt numbers as a direct result of the increased wall shear stress.

- The $H_{1}$ heat transfer (surface and volumetric) at the Hartmann wall is enhanced more than the side-wall due to the different boundary layer behaviour. As a result, overall heat transfer with long Hartmann walls is better than that with long side walls of the same geometry for $H a>1$.

- Increasing the magnetic field generally enhances both peripherally mean $\mathrm{H}_{2}$ surface and volumetric Nusselt numbers. Ducts with long Hartmann walls (short side walls) have little, if any, effect for a given $\mathrm{Ha}$; ducts with short Hartmann walls (long side walls) exhibit a progressive reduction in heat transfer as the aspect ratio increases.

- In the limit of large $\mathrm{Ha}$, Shercliff flow approximates slug flow. This is reflected in the very rapid increase in volumetric Nusselt number with $\mathrm{Ha}$ for the $\mathrm{H}_{2}$ case.

\subsection{Hunt-II Flow}

- Heat transfer in this case is determined not only by the very different boundary layer thicknesses near Hartmann and side walls but by the suppression of the core flow and the development of jets near the side walls as $\mathrm{Ha}$ increases.

- Despite the wall boundary layer behaviour, the $H_{1}$ heat transfer (surface and volumetric) at the side wall is enhanced more than at the Hartmann wall due to the combination of core flow suppression and jet development. As a result, heat transfer with long side walls is better than that with long Hartmann walls of the same geometry (unlike the Shercliff case).

- Increasing the magnetic field generally enhances both peripherally mean $\mathrm{H}_{2}$ surface and volume Nusselt numbers as a result of the increased wall shear stress. This effect is reduced for ducts with short Hartmann walls and can be reversed for extremely short Hartmann walls.
- For uniform peripheral heat flux $u H_{2}$, there is an optimal aspect ratio $a / b \approx 0.25$ for high $\mathrm{Ha}$.

- The effect of cooling jets near side walls is substantial - to the point where subcooling is exhibited, but in opposition to this, Hartmann wall heat transfer is greatly reduced due to core supression, despite the strong shear stresses at the wall.

The real value in these results lies in their use as the underpinning correlations in whole plant systems codes, mirroring their fission counterparts.

[1] Wong, C., Malang, S., Sawan, M., Dagher, M., Smolentsev, S., Merrill, B., Youssef, M., Reyes, S., Sze, D. K., Morley, N. B., et al., 2006. "An overview of dual coolant pb-17li breeder first wall and blanket concept development for the us iter-tbm design". Fusion Engineering and Design, 81(1), pp. 461-467.

[2] Smolentsev, S., Moreau, R., Bühler, L., and Mistrangelo, C., 2010. "Mhd thermofluid issues of liquid-metal blankets: phenomena and advances". Fusion Engineering and Design, 85(7), pp. 1196-1205.

[3] Patel, A., Pulugundla, G., Smolentsev, S., Abdou, M., and Bhattacharyay, R., 2018. "Validation of numerical solvers for liquid metal flow in a complex geometry in the presence of a strong magnetic field". Theoretical and Computational Fluid Dynamics, 32(2), Apr, pp. 165-178.

[4] Gajbhiye, N. L., Throvagunta, P., and Eswaran, V., 2018. "Validation and verification of a robust 3-d mhd code". Fusion Engineering and Design, 128, pp. $7-22$.

[5] Shercliff, J., 1953. "Steady motion of conducting fluids in pipes under transverse magnetic fields". Mathematical Proceedings of the Cambridge Philosophical Society, 49(01), pp. 136-144.

[6] Hunt, J. C. R., 1965. "Magnetohydrodynamic flow in rectangular ducts". Journal of Fluid Mechanics, 21(4).

[7] Wolfendale, M. J., and Bluck, M. J., 2015. "A coupled systems code-cfd mhd solver for fusion blanket design". Fusion Engineering and Design, 98-99, pp. 1902 - 1906. Proceedings of the 28th Symposium On Fusion Technology (SOFT-28).

[8] Bluck, M., and Wolfendale, M., 2015. "An analytical solution to electromagnetically coupled duct flow in mhd". Journal of Fluid Mechanics, 771, pp. 595-623.

[9] Bluck, M. J., Wolfendale, M. J., and Marquis, A. J., 2015. "An analytical solution to the heat transfer problem in shercliff flow". International Journal of Heat and Mass Transfer, 86, pp. 542-549.

[10] Bluck, M. J., and Wolfendale, M. J., 2017. "An analytical solution to the heat transfer problem in thick-walled hunt flow". International Journal of Heat and Fluid Flow, 64, pp. 103-111.

[11] Blūms, E., Mikhaŭlov, Y., and Ozols, R., 1987. Heat and Mass Transfer in MHD Flows. World Scientific Publishing.

[12] Zniber, K., Oubarra, A., and Lahjomri, J., 2005. "Analytical solution to the problem of heat transfer in an MHD flow inside a channel with prescribed sinusoidal wall heat flux". Energy Conversion and Management, 46(7-8), pp. $1147-1163$.

[13] Ying, A., Lavine, A., and Tillack, M., 1989. "The effect of Hartmann and side layers on heat transfer in magnetohydrodynamic flow". Fusion Technol., 15.

[14] Sidorenkov, S., Hua, T., and Araseki, H., 1995. "Magnetohydrodynamics and heat transfer benchmark problems for liquid-metal flow in rectangular ducts". Fusion Eng. Des., 27, pp. 711 - 18.

[15] Takase, K., and Hasan, M., 1995. "Heat transfer characteristics of rectangular coolant channels with various aspect ratios in the plasma-facing components under fully developed MHD laminar flow". 16th IEEE/NPSS Symposium Fusion Engineering, SOFE '95. Seeking a New Energy Era (Cat. No.95CH35852), vol.2, pp. $1538-41$.

[16] Tezer-Sezgin, M., 1994. "Boundary element method solution of MHD flow in a rectangular duct". Int. J. Numer. Methods Fluids, 18(10), pp. 937 -52 .

[17] Al-Khawaja, M. J., and Selmi, M., 2009. "Numerical solutions of two heat transfer limits of MFM square duct flow using matlab program". International Journal for Computational Methods in Engineering Science and Mechanics, 10(1), pp. 102-107. 
[18] Al-Khawaja, M., and Selmi, M., 2006. "Highly accurate solutions of a laminar square duct flow in a transverse magnetic field with heat transfer using spectral method". Journal of Heat Transfer, 128(4), pp. 413-417.

[19] Lahjomri, J., Zniber, K., Oubarra, A., and Alemany, A., 2003. "Heat transfer by laminar Hartmann's flow in thermal entrance region with uniform wall heat flux: the Graetz problem extended". Energy Conversion and Management, 44(1), pp. 11-34.

[20] Shahmardan, M. M., Norouzi, M., Kayhani, M. H., and Amiri Delouei, A., 2012. "An exact analytical solution for convective heat transfer in rectangular ducts". Journal of Zhejiang University SCIENCE A, 13(10), pp. 768-781. 